\title{
A Negotiation Approach to Support the Strategies Alignment Process in Collaborative Networks
}

\author{
Beatriz Andres 1,*(1) and Vicente Javier Blanes ${ }^{2}$ \\ 1 Research Centre on Production Management and Engineering (CIGIP), Universitat Politècnica de València, \\ Escuela Politécnica Superior de Alcoy, Calle Alarcón, 03801 Alcoy, Spain \\ 2 Industrial Engineer, by the Universitat Politecnica de València Alcoy, Calle Benimarfull, 03802 Alcoy, Spain; \\ viblaca@gmail.com \\ * Correspondence: bandres@cigip.upv.es
}

Received: 9 March 2020; Accepted: 29 March 2020; Published: 1 April 2020

\begin{abstract}
This paper proposes a negotiation approach to support the strategies alignment (SA) collaborative process. The negotiation approach is presented as a complementary mechanism to deal with the SA process. The strategies alignment negotiation approach (SA-NA) considers three different levels of collaboration, which differ by the accurateness of information and amount of data exchanged among the collaborative enterprises. Accordingly, three negotiation processes are proposed, equivalent to the three collaboration levels identified. This paper describes from a conceptual and mathematical point of views the phases of the SA-NA to carry out at each collaboration level. The SA-NA enables users to identify aligned strategies to be activated by the collaborative network $(\mathrm{CN})$ partners. The main aim of the SA-NA is to identify those aligned strategies that satisfy all the $\mathrm{CN}$ enterprises, allowing users to achieve the objectives and performance levels required at the enterprises' level while the network performance is maximized. The SA-NA enables CN partners to negotiate and achieve a suitable solution for all the $\mathrm{CN}$ enterprises, promoting sustainable collaboration among the partners participating in the $\mathrm{CN}$ through the activation of aligned strategies.
\end{abstract}

Keywords: strategies alignment; negotiation process; collaboration level; sustainable collaboration

\section{Introduction}

Manufacturing enterprises are more and more aware of establishing collaborative relationships with the network partners due to associated advantages [1] and as a response to the present interconnected and volatile business environment. The participation of small and medium-sized enterprises (SMEs) in collaborative networks (CNs) enhances their competitiveness by increasing their agility, responsiveness, and adaptability to deal with the rapid market evolutions and the globalization of business. Nevertheless, the participation in a CN has associated challenges [2], especially for SMEs, which are derived from the lack of resources and capabilities and the limitations associated to cultural barriers [3].

As CNs consist of autonomous partners, each one defines its own objectives and formulates its own strategies. The ensuing strategy diversity may result in conflict situations among enterprises within the same $\mathrm{CN}$, since contradictions among the strategies formulated might emerge. According to Andres and Poler [4], these contradictions appear when the strategies activated in one enterprise negatively influence in the objectives defined by other enterprises of the network. The lack of coherence and concordance among the formulated strategies leads to its misalignment. The connotations regarding the strategies' misalignment are related with the objectives' achievement at the enterprise level, reducing their performance levels and influencing on the sustainability of the collaborative relationships established. If the conflicts that arise, derived from the lack of strategies alignment, are 
not tackled, the strategies misalignment could lead, in the long term, to the breakdown of the $\mathrm{CN}$. Success when obtaining higher levels of performance in a $\mathrm{CN}$ is directly related to the activation of a proper combination of strategies in each enterprise belonging to the network.

The concept of alignment has been studied in different research areas, including the $\mathrm{CN}$ perspective to support the formally representation and resolution of the strategies' alignment process from a holistic view. In the light of this, Andres and Poler [4] propose a complete approach, consisting of a model, a method, and a tool to (i) to identify the degree of alignment of the strategies, from a holistic perspective, and (ii) to propose the activation of the aligned strategies. The strategies alignment model (SAM) allows considering all the strategies formulated by all the partners and model the influence that these strategies exert on the wide diversity of objectives defined, regardless of their nature and type, taking into account the $\mathrm{CN}$ context.

Enterprises participating in a $\mathrm{CN}$ interchange partially or entirely all the information as regards the objectives and the strategies, formulated to achieve such objectives. The degree of collaboration depends on the level of information exchanged. Besides the collaboration degree, $\mathrm{CN}$ partners have to identify which type of collaboration are going to carry out, centralised or decentralised. On the one hand, centralised decision-making models (CDM) are characterised by having a broker node, that has access to all the information of the $\mathrm{CN}$ enterprises. The level of trust in CDM is maximum and the broker performs the decision-making to optimize a multi-objective model that represent all the network partners [5-7]. On the other hand, in decentralised decision-making models (DDMs), each enterprise of the $\mathrm{CN}$ deals with its own decisions and optimise its own objectives. In DDMs, there are as many decision makers as enterprises within the CN. Nevertheless, we are tackling the collaboration research area so that, within the decision-making process, a certain degree of collaboration is exerted. $\mathrm{CN}$ partners will consider the decisions of the rest of enterprises in accordance with the agreed-upon degree of collaboration. In DDM, collaborative procedures are needed to supervise the interchange of information and coordinate the $\mathrm{CN}$ partners' decisions [5-8]. In the topic under research-the strategies alignment process-the CDM perspective is characterised by the centralised implementation of the SAM enterprises obtaining optimal solutions at network level. In the DDM perspective, each enterprise calculates its own SAM, obtaining optimal solutions at the enterprise level. Therefore, a negotiation process is to be applied to achieve good solutions at the enterprise level and good or optimal solutions at the network level.

When the network enterprises work from a decentralised collaborative perspective, the decision of identifying the aligned strategies becomes more difficult because negotiations mechanisms are required, and such mechanisms have to be accurately defined so that the collaborative relationship does not end in conflict, damaging the sustainability of the $\mathrm{CN}$. Therefore, the enterprises belonging to the network have to concur with all the activation of strategies and the timeframe in which to activate them so that the performance of the network is maximised and the decisions taken in relation to the activation of strategies are to the liking and benefit of all the $\mathrm{CN}$ partners. The current paper proposes three negotiation processes that correspond to three different collaborative levels, in which a low, a medium, and the full amount of information is interchange. The negotiation processes will allow users to identify the strategies that exert positive influences in the all objectives defined, dealing with potential misalignments, thus reducing conflicts and contradictions with the main aim achieving sustainable collaboration among the $\mathrm{CN}$ enterprises.

In order to support the implementation of the SAM when decentralized decision making is carried out, a negotiation approach is developed as a complementary mechanism to deal with the strategies alignment collaborative process. This will fulfill the future research line defined in Andres and Poler [4] alongside the application of the SAM in a distributed context. Therefore, the main aim of this paper is to provide a set of negotiation mechanisms to deal with the strategies misalignment problem in order to establish long-term and sustainable collaborative relationships.

In order to address the proposed objective, the paper is organized as follows: Section 2 introduces the materials and methods of the paper, including the state of the art on the importance of negotiation 
mechanisms in $\mathrm{CN}$ processes, the description of the strategies alignment process focusing on the objectives and strategies definition, and the three collaboration levels defined for the negotiation process. Section 3 defines the strategies alignment negotiation approach considering each of the collaboration levels previously defined. Finally, in Section 4, conclusions and future research lines are considered.

\section{Materials and Methods}

\subsection{Theoretical Background}

In order to develop the proposed negotiation approach to support the strategies alignment process in $\mathrm{CN}$ from a decentralized collaborative perspective, this paper is based on a theoretical body of knowledge regarding the following elements:

- The collaborative network $(\mathrm{CN})$ discipline considers networks as a variety of autonomous entities, geographically distributed and heterogeneous in operational terms and objectives, which collaborate to achieve common or compatible goals. In CNs, the network partners can achieve goals that would not be possible or would be more costly if organisations worked individually. $\mathrm{CN}$ discipline contributes to the theoretical base concepts of virtual organisations, consortium formation, and collaboration in general. It provides methods and tools for its application in modelling CNs [9]. The relevance of Collaborative Supply Chain Networks (CSCNs) is established as a response to the present interconnected and volatile business environment.

- Collaborative processes are processes involving multiple partners, each one playing a different role. The processes are defined based on business interaction protocols that are commonly agreed upon by the involved partners. Multiple entities collaboratively participate in these processes. Therefore, collaborative mechanisms are required to support enterprises in order to properly establish them and reduce any potential drawbacks, especially in SMEs $[6,10]$.

- Centralised Decision Making (CDM) focuses on the generation of centralised decision-making models in which a single partner (or central node) is familiarised with all the information systems. The central node is in charge of the system planning and has the power to manage the operations performed by all the network partners. The central node performs the decision making in terms of optimising the objectives of the entire network [5,7].

- Decentralised Decision Making (DDM) focuses on the establishment of decentralised decision-making models in which each individual independent network entity makes its own decisions, trying to optimise its own objectives. More than one decision maker is identified. Depending on the collaboration degree, the nodes will take into account (to a greater or lesser extent) the decisions of other nodes. Collaborative mechanisms are needed to coordinate the partners' decisions and exchange information $[5,7]$.

- Alignment is a background element of the models, guidelines, and tools proposed in the literature to deal with problems related to the alignment $[4,10]$.

- Negotiation mechanisms involve a key factor to deal with the networks' evolution toward collaboration. The management of coordination mechanisms allows the networked partners to manage operations in a coordinated way [11], integrating all the network partners as from a decentralised decision-making perspective in order to obtain and achieve fair distributions of benefits derived from the collaboration. Negotiation mechanisms are required in order to align the performance levels in order to produce equitable sharing between all the collaborative partners.

- Sustainability is the need of an effective and sustainable eco-efficient production and distribution systems to achieve collaborative logistic models of operation Researchers have stressed the need for the adoption of new sustainable business for organizations and increased forms of cooperation across the whole value chain in order for an organization to improve both their profitability and value creation and their environmental performance $[12,13]$. The requirements resulting from participation in a $\mathrm{CN}$ must be properly addressed by the enterprises in order to establish good relations and create sustainable CNs. 


\subsection{State of the Art: The Importance of Negotiation Mechanisms in CN Processes}

Participation in collaborative processes among $\mathrm{CN}$ partners requires the generation of models, guidelines, and tools, including negotiation mechanisms. Negotiation protocols are especially necessary when dealing with decentralized decision-making processes, which are characterized by looking for acceptable solutions at the enterprise level, generating optimal results at the network level. A CN behaves as a DDM [5], in which different decisional units coexist, and coordination and negotiation mechanisms are required to manage the alignment of individual objectives and strategies, with the aim of fulfilling the requirements of all the $\mathrm{CN}$ partners and achieve sustainable and long-term relationships. The design of negotiation processes is focused on the definition of mechanisms to coordinate decisions and interchange data and incentive plans to distribute the gains that originate from the collaborative processes [6]. Negotiation mechanisms have to be characterized by integrating all the partners' decisions by equally considering all the $\mathrm{CN}$ partners [14]. In terms of negotiation mechanisms, the process of contracts negotiation is widely studied in the literature to achieve greater levels of collaboration among $\mathrm{CN}$ enterprises in order to fulfil major consensus [15]. Accordingly, the definition of negotiation mechanisms to manage contract bargaining in $\mathrm{CN}$ are crucial \{Formatting Citation\}.

Negotiation mechanisms have been studied in different collaborative process, including production, inventory, and distribution collaborative planning processes. In such processes, negotiation mechanisms are used to address contradictory objectives among partners, developing scenarios that consider all the $\mathrm{CN}$ partners [16]. Thus, planning processes, initially local, can be extended toward different planning domains [17], thus achieving beneficial plans for all the network partners [18]. The definition of pre-agreed business rules to assess and compare alternatives using performance measurement techniques are of great value to decentralised planning $[19,20]$.

The collaborative process of sharing costs and profits also requires negotiation mechanisms to balance the distribution profits among $\mathrm{CN}$ enterprises [21]. In this regard, Andres and Poler [22] propose a methodology to handle the sharing of profits in $\mathrm{CN}$ enterprises. At the operational level of decision making, a lot sizing collaborative process requires negotiation procedures to identify the optimal batch sizes that adapt to the $\mathrm{CN}$ partners' capacities at the same time that customer demand is fulfilled [23]. The collaborative order promising process also needs negotiation mechanisms to manage $\mathrm{CN}$ enterprise activities that respond to the customers' needs and orders. Moreover, negotiation actions to exchange information of the enterprises' capacity and availability are also a key factor to deal with the order promising process [24]. In the scheduling process, negotiation mechanisms have to be considered in order to obtain joint and agreed scheduling plans between $\mathrm{CN}$ enterprises [25]. The process of information sharing itself is crucial for any negotiation process [26].

The strategies alignment process applies concepts such as trust [27], personal circumstances [28], and emotions [29] that inevitably appear in any negotiation process affecting the agreements reached. The strategies alignment process addressed in this paper also requires the design of negotiation mechanisms to achieve agreements on the enterprises that collaborate from a decentralized decision-making perspective [30]. Research in the collaborative process of establishing aligned strategies aims to generate models, guidelines, and tools that enable enterprises to activate the strategies that benefit all the collaborative enterprises. Andres and Poler [4] proposed the SAM to maximize performance indicators when a set of strategies are activated, allowing users to identify the strategies that, when activated, are of benefit to the objectives of the enterprise and that positively affect the performance indicators and the achievements of the rest of the $\mathrm{CN}$ enterprises.

\subsection{Strategies Alignment Model (SAM)}

The success of the $\mathrm{CN}$ is determined by the increase of the performance level, the reduction of strategies misalignments, and the generation of more stable and sustainable collaborative partnerships. Strategies alignment is considered a key process to allow enterprises to achieve the required levels of agility and flexibility. The strategies alignment process leads to the improvement of collaborative relationships between the enterprises, increasing the $\mathrm{CN}$ sustainability [31]. The developed research 
aims to provide a better understanding on the ways to establish sustainable collaborative relationships between the partners within a $\mathrm{CN}$ when operating from a decentralised perspective. In this regard, we propose a negotiation approach to support the strategies alignment in a $\mathrm{CN}$.

The strategies alignment model (SAM) [4] uses the system dynamics method to represent causal relations between the strategies formulated and the objectives defined by each of the $\mathrm{CN}$ enterprises. The SAM proposes a mathematical notation to represent the influences that strategies have on performance indicators with the aim of measuring the objectives. The SAM considers that the activation of a particular strategy in a specific enterprise of the $\mathrm{CN}$ influences the performance indicators of the rest of the $\mathrm{CN}$ enterprises and, therefore, the global network performance level. The SAM consolidates the conceptualisation of intra- and inter-enterprise influences. Intra-enterprise influences allow users to model the impact of a specific enterprise when certain strategies are adopted by that enterprise. Inter-enterprise influences apply to the impacts when the rest of the $\mathrm{CN}$ partners adopt their strategies.

\subsubsection{Objectives Definition}

The $\mathrm{CN}$ enterprises define the objectives, and to measure their achievement, a set of associated performance indicators are determined. The objectives are codified according to the following mathematical notation: $o_{i x}$ represents the objective $x$ defined in enterprise $i$. The following parameters enables $\mathrm{CN}$ enterprises to feature the objectives and performance indicators needed to feed the strategies alignment model. For more detained information, we refer the reader to Andres and Poler [4] and Andres [30]:

- Objectives defined by each enterprise: $\mathrm{o}_{\mathrm{ix}}$;

- Performance indicators to measure the achievement of the $\mathrm{o}_{\mathrm{ix}}: \mathrm{kpi}_{\mathrm{ik}}$, where $\mathrm{i}$ is the enterprise and $\mathrm{k}$ is the index of the performance indicator;

- Maximum increase of performance indicator estimated by the enterprise: $\Delta \mathrm{kpi}_{\mathrm{ik}} \max _{\text {; }}$;

- The value from which the associated $\mathrm{kpi}_{\mathrm{ik}}$ is influenced when a strategy is defined by an enterprise is activated: Threshold_kpi $i_{i k}$. Under the value defined by Threshold_kpi $i_{i k}$, the influence of the strategy is not considered;

- Minimum level of increase for the $\mathrm{kpi}_{\mathrm{ik}}$ that the enterprise I accepts, once the Threshold_kpi $\mathrm{i}_{\mathrm{ik}}$ is calculated: $\Delta \mathrm{kpi}_{\mathrm{ik} \_} \min$;

- Importance that the $\mathrm{kpi}_{\mathrm{ik}}$ has for Enterprise $\mathrm{i}: \mathrm{w}_{\mathrm{ik}}$.

\subsubsection{Strategies Definition}

The strategies formulated by all the $\mathrm{CN}$ enterprises are identified and developed to fulfil the objectives. Considering all the strategies formulated, the SAM will select those that have more possibilities to be adopted. The SAM aids CN enterprises to identify which strategies to adopt amongst all those formulated in order to achieve higher levels of performance and alignment. The strategies are codified according to the following mathematical notation: $\operatorname{str}_{\text {is }}$ represents the strategy s defined by enterprise $i$. When $\operatorname{str}_{\text {is }}$ is activated, it will have a positive or negative influence on the $\mathrm{kpi}_{\mathrm{ik}}$, enabling the user to identify the inter- and intra-enterprise influence values. The following parameters enable $\mathrm{CN}$ enterprises to feature the strategies needed to compute the SAM. For more detained information, we refer the reader to Andres and Poler [4] and Andres [30].

- Formulation of strategies by the $\mathrm{CN}$ enterprises: $\operatorname{str}_{\mathrm{is}}$. $\mathrm{The} \mathrm{st}_{\mathrm{is}}$ is able to be split up into units of strategy $u_{-}$str $_{\text {is }}$ for its activation, which acts as a decision variable;

- Starting time in which to activate the formulated $\operatorname{str}_{\text {is }}$ : $\mathrm{ti}_{-} \mathrm{str}_{\mathrm{is}}$ acts as a decision variable;

- Influence value;

- val_str ${ }_{\text {is_- }} \mathrm{kpi}_{\mathrm{ik}}$ measures the impact that $\operatorname{str}_{\mathrm{is}}$ of enterprise $\mathrm{i}$, has on the $\mathrm{kpi}_{\mathrm{jk}}$, of enterprise $\mathrm{i}$;

○ val_str ${ }_{\mathrm{is} \_} \mathrm{kpi}_{\mathrm{jk}}$ measures the impact that $\operatorname{str}_{\mathrm{is}}$ of enterprise $\mathrm{i}$, has on the $\mathrm{kpi}_{\mathrm{jk}}$, of enterprise $\mathrm{j}$; 
$\bigcirc \quad$ val_str ${ }_{j s}-k_{p i} i_{j k}$ measures the impact that $\operatorname{str}_{j \mathrm{~s}}$ of enterprise $\mathrm{j}$, has on the $\mathrm{kpi}_{\mathrm{jk}}$, of enterprise $\mathrm{j}$; $\bigcirc \quad$ val_str ${ }_{j s}{ }_{-} \mathrm{kpi}_{\mathrm{ik}}$ measures the impact that $\mathrm{str}_{\mathrm{js}}$ of enterprise $\mathrm{j}$, has on the $\mathrm{kpi}_{\mathrm{ik}}$, of enterprise $\mathrm{i}$.

- Strategy stris activating cost (monetary units): c_stris;

- Time units between the starting time of an activated strategy ti_stris, and the moment in which such strategy stris starts impacting on the value of the kpiik. Delay influence of the $\operatorname{str}_{i s}: d_{1} s t_{i s}$;

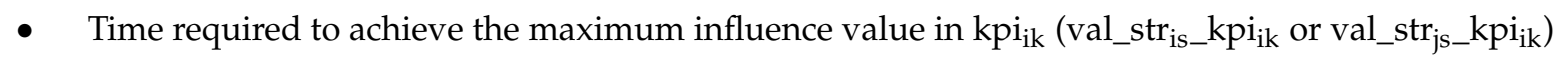
counting from $\mathrm{d}_{1 \_} \operatorname{str}_{\mathrm{is}}: \mathrm{d}_{2 \_} \operatorname{str}_{\text {is }}$;

- Full time span in which $\operatorname{str}_{\text {is }}$ is active, in time period units: $d_{4 \_} s t_{\text {is; }}$;

- Enterprise i budget, in monetary units, to fund in the $\operatorname{str}_{\text {is }}$ activation: $b_{i}$.

\subsection{Collaboration Levels in the Negotiation Process}

The main aim of this paper is to provide a set of negotiation mechanisms to solve the strategies misalignment problem in order to establish long-term and sustainable collaborative relationships. When enterprises collaborate, a low, a medium, or the full amount of information can be exchanged. Depending on the amount of information exchanged, three collaboration levels are identified. Collaborative Scenario 1 (CS1) corresponds to the low exchange of information. Collaborative Scenario 2 (CS2) corresponds to the medium exchange of information. Finally, Collaborative Scenario 3 (CS3) corresponds to the full amount of information exchange. In the non-collaborative scenario (NCS), enterprises do not exchange information [30].

\subsubsection{Non-Collaborative Scenario (NCS)}

The network enterprises do not exchange information (Figure 1) and work separately. The enterprise i decides the strategies to activate and only considers its own data; thus computing the SAM by contemplating its own objectives $\mathrm{O}_{\mathrm{ix}}$ and strategies $\operatorname{str}_{\mathrm{is}}$.

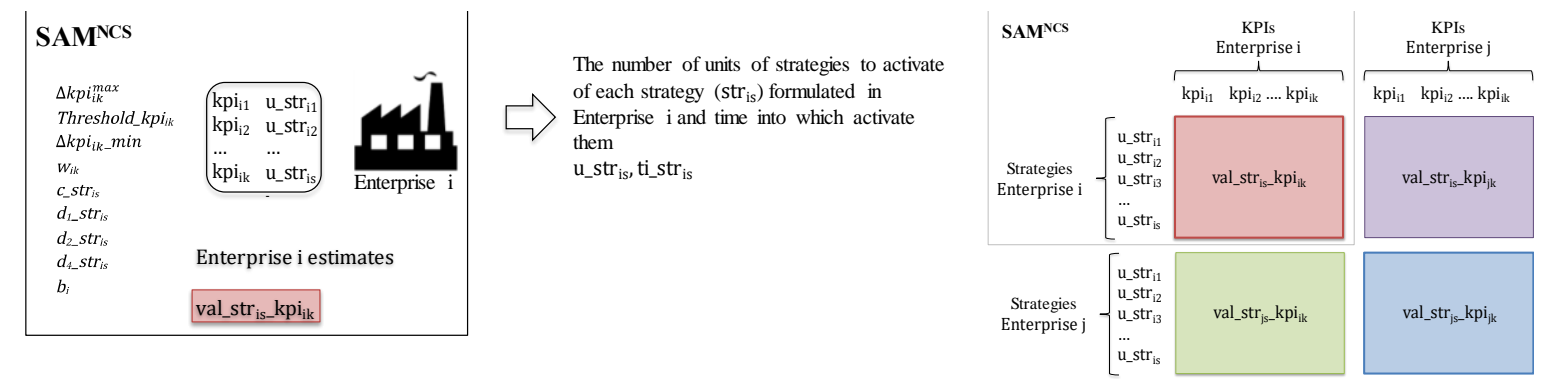

Figure 1. Non-collaborative scenario $\left(\mathrm{SAM}^{\mathrm{NCS}}\right)$.

\subsubsection{Collaborative Scenario 1 (CS1)}

A low amount of information is exchanged Figure 2. $\mathrm{CN}$ enterprises exchange information about the performance indicators, including the val_str ${ }_{i s \_} \mathrm{kpi}_{\mathrm{ik}}$ and the val_str $\mathrm{is}_{-} \mathrm{kpi}_{\mathrm{jk}}$, whose values are determined by each $\mathrm{CN}$ partner. Enterprise $\mathrm{i}$ uses the information that enterprise $\mathrm{j}$ shares about its performance indicators, estimating the influence value val_str ${ }_{i s}{ }_{-} \mathrm{kpi}_{\mathrm{jk}}$. The SAM is computed by each enterprise in isolation, considering how its activated strategies impact its performance indicators (val_str $\left.{ }_{i s \_} \mathrm{kpi}_{\mathrm{ik}}\right)$ and the performance indicators of other $\mathrm{CN}$ nodes $\left(\mathrm{val}_{-} \mathrm{str}_{\mathrm{is} \_} \mathrm{kpi}_{\mathrm{jk}}\right)$.

\subsubsection{Collaborative Scenario 2 (CS2)}

A medium amount of information is exchanged (Figure 3). The information of performance indicators that is interchanged entails the $\mathrm{kpi}_{\mathrm{ik}}$, Threshold_kpi $\mathrm{ik}_{\mathrm{k}}, \mathrm{w}_{\mathrm{ik}}, \Delta \mathrm{kpi}_{i k \_} \mathrm{min}$, and $\Delta \mathrm{kpi}_{\mathrm{ik}} \max$. Strategies interchange data involves $\mathrm{d}_{1 \_} \operatorname{str}_{\mathrm{is}}, \mathrm{c} \_\operatorname{str}_{\mathrm{is}}, \mathrm{b}_{\mathrm{i}}, \mathrm{d}_{2} \_\operatorname{str}_{\mathrm{is}}$, and $\mathrm{d}_{4 \_} \mathrm{str}_{\mathrm{is}}$, although the strategy definition remains confidential. All $\mathrm{CN}$ enterprises estimate val_str ${ }_{i s}{ }_{\mathrm{k}} \mathrm{kp}_{\mathrm{ik}}$. Using the minimum information interchanged, $\mathrm{CN}$ enterprises identify the inter-enterprise influence values: 
- enterprise i determines val_stris_- $\mathrm{kpi}_{\mathrm{j} \mathrm{k}}$;

- enterprise j establishes val_str ${ }_{j \_} \_\mathrm{kpi}_{\mathrm{ik}}$;

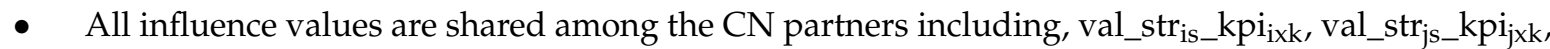

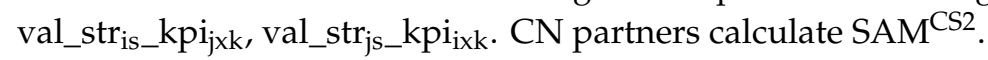
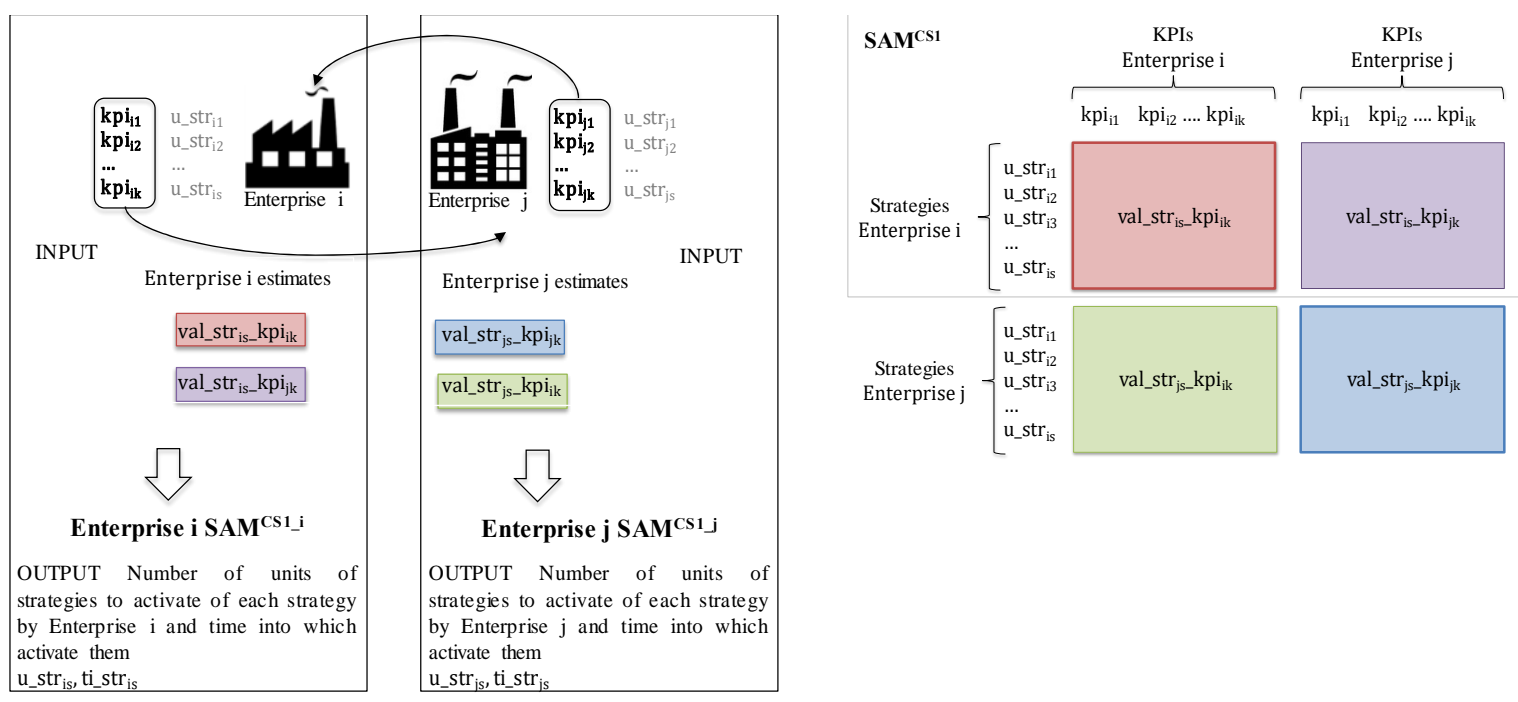

Figure 2. Collaborative Scenario $1\left(\mathrm{SAM}^{\mathrm{CS} 1}\right)$.

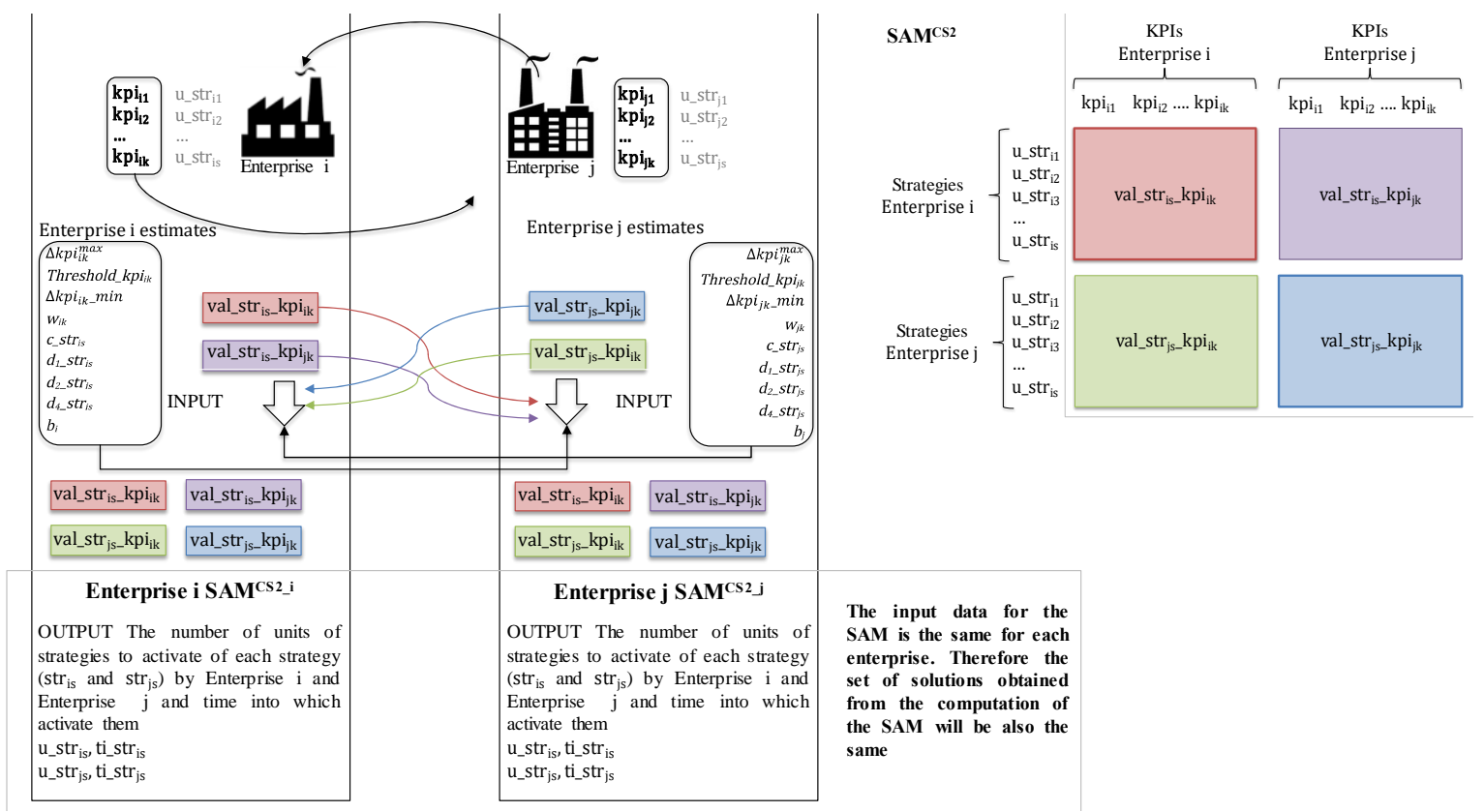

Figure 3. Collaborative Scenario $2\left(\mathrm{SAM}^{\mathrm{CS} 2}\right)$.

\subsubsection{Collaborative Scenario 3 (CS3)}

There is a full exchange of information of the performance indicators, and the strategies (Figure 4) are deployed. The information exchanged about performance indicators includes $\Delta \mathrm{kp}_{\mathrm{ik}} \max _{\text {, }}$ Threshold_kpi $\mathrm{ik}_{\mathrm{ik}}, \Delta \mathrm{kpi}_{\mathrm{ik}} \mathrm{min}_{\mathrm{ik}} \mathrm{w}_{\mathrm{ik}}$, and $\mathrm{kpi}_{\mathrm{ik}}$. Data characterising the strategies is shared, including $\mathrm{u}_{-} \operatorname{str}_{\mathrm{is}}, \mathrm{d}_{1 \_} \mathrm{str}_{\mathrm{is}}, \mathrm{c} \_\mathrm{str}_{\mathrm{is}}, \mathrm{b}_{\mathrm{i}}, \mathrm{d}_{2} \mathrm{str}_{\text {is }}$, and $\mathrm{d}_{4 \_} \mathrm{str}_{\mathrm{is}}$. Enterprise $\mathrm{i}$ individually defines and shares intra-enterprise values val_str ${ }_{i s \_} \mathrm{kpi}_{\mathrm{ixk}}$ with enterprise $\mathrm{j}$. Enterprise $\mathrm{j}$ does the same with val_str $\mathrm{j}_{\mathrm{j} \_} \mathrm{kpi}_{\mathrm{jxk}}$. Finally, all the CN partners conjointly define the inter-enterprise influence values (val_str ${ }_{\text {is_- }} \mathrm{kpi}_{\mathrm{jxk}}$ and val_str $\left.{ }_{j s \_} k i_{i x k}\right)$. 
In CS3, all the CN enterprises have the same values for all the input data feeding the SAM. Nevertheless, each CN partner calculates its own SAM ${ }^{\mathrm{CS} 3}$ to establish a DDM process to address the alignment of strategies problem.

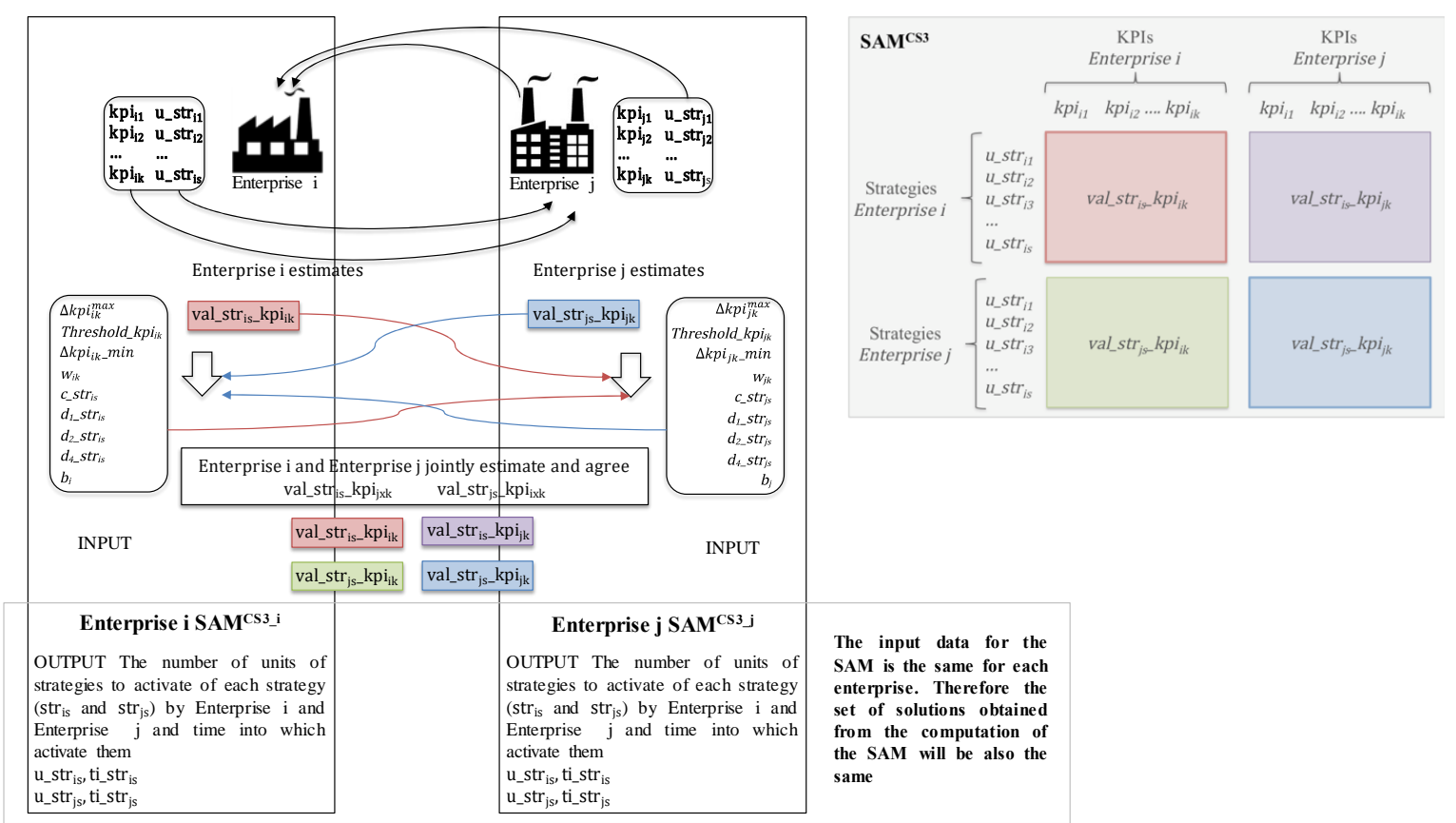

Figure 4. Application of the strategies alignment model (SAM) in Collaborative Scenario $3\left(\mathrm{SAM}^{\mathrm{CS} 3}\right)$.

\section{Results: Strategies Alignment Negotiation Approach}

The strategies' alignments process computed from a centralised perspective provides an optimal solution. Nevertheless, the calculation of the SAM in a decentralised perspective requires the implementation of a negotiation process. In the decentralised scenario, each $\mathrm{CN}$ enterprise $\mathrm{i} \in \mathrm{I}$ implements the strategies alignment model SAM ${ }^{i}$; therefore, there will be as many SAMs as enterprises, I, in the network. The CN partners will select the SAM solution that best fits its objectives. The output of each $S_{A M}{ }^{i}$ determines the units of strategies for adoption by a CN partner, $u \_s t r$ is, and the time period in which to adopt such strategies, $\mathrm{ti}_{-} \mathrm{str}_{\mathrm{is}}$. In the SA-NA, the CN partners' shares the solutions are generated in the $S A M^{i}$ resolution. The enterprises follow iterative process in order to exchange information to facilitate the negotiation and the achievement of agreement, thus dealing with the process of identifying which strategies to adopt and when. In each iterative process, every single enterprise analyses the proposals made by the rest of network partners. Then, all the CN enterprises negotiate the alternative solutions that generate a performance as close to the optimum as possible for each partner. Minimum and maximum boundaries of performance have to be defined by each enterprise, and alternative of solutions will be raised considering the defined limits. The process of negotiation is finished when the $\mathrm{CN}$ partners achieve their objectives or when the agreed number of iterations runs out.

During the SA negotiation process, all the CN enterprises have the same consideration so that stronger $\mathrm{CN}$ enterprises do not receive advantages in terms of greater performance levels compared to the weaker CN enterprises. Nevertheless, as the solution of the SAM looks for the maximisation of the CN performance level, some enterprises could potentially achieve higher levels of performance at the expense of other CN enterprises' performance. Three negotiation processes are proposed and described, as each CS has different characteristics. Next, the three processes of negotiation are explained, according to the three CSs identified (for further details, the reader is invited to read Andres [30]). The SA-NA consists of three negotiation processes created for each level of collaboration-CS1, CS2, and CS3-in order to identify the solutions that best fits each $\mathrm{CN}$ enterprise and the whole $\mathrm{CN}$ performance level. 
Each negotiation process for each collaboration level is hereafter described. Moreover, Figures 5-7 gives a broad view of the steps to carry out in each NP_CS1, NP_CS2, and NP_CS3, respectively.

\subsection{Negotiation Process CS1 (NP_CS1)}

NP_CS1 is applied by those CN partners that establish CS1. The NP_CS1 diagram is presented in Figure 5. NP_CS1 enables CN partners to negotiate the values of the decision variables $u_{-}$str $_{\text {is }}^{\mathrm{CS} 1}$, ti_str ${ }_{\text {is }}$ obtained in the SAM when the CS1 is carried out. Table 1 depicts the parameters used in the NP_CS1. Then, the steps to follow in the NP-CS1 are detailed in the following sections.

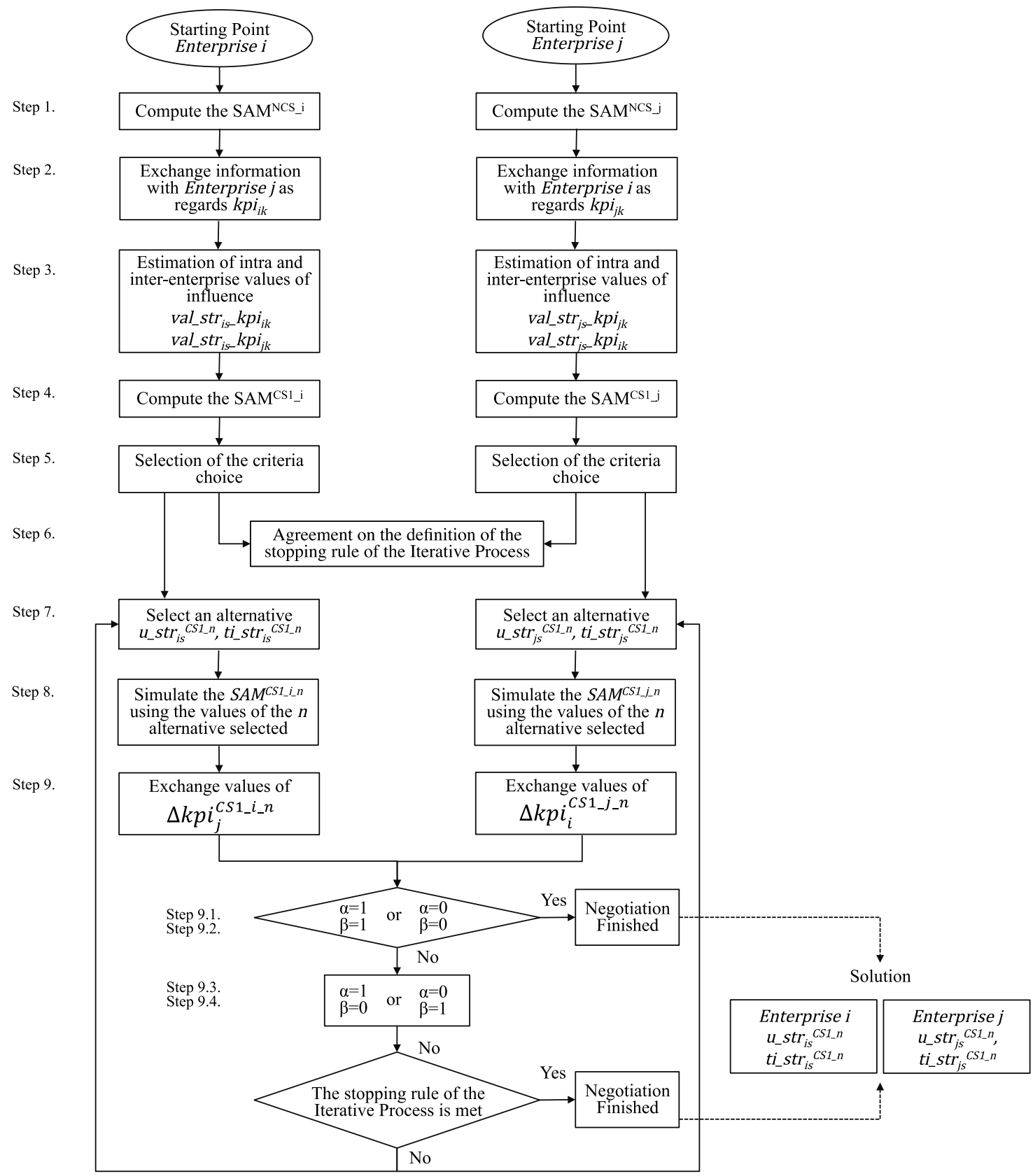

Figure 5. Negotiation Process CS1. 
Table 1. NP_CS1 parameters.

\begin{tabular}{|c|c|}
\hline Notation & Definition \\
\hline $\mathrm{kpi}_{\mathrm{ik}}$ & Enterprise i performance indicators \\
\hline val_stris_kpi ${ }_{i k}$ & $\begin{array}{l}\text { Intra-enterprise influence values estimated. Impact value that } s \mathrm{rr}_{\mathrm{is}} \text { of enterprise } \mathrm{i} \text { has on } \\
\mathrm{kpi}_{\mathrm{ik}} \text { of enterprise } \mathrm{i}\end{array}$ \\
\hline val_str ${ }_{i s \_} \mathrm{kpi}_{\mathrm{jk}}$ & $\begin{array}{l}\text { Inter-enterprise influence values estimated. Impact value that stris } \text { of enterprise } i \text { has on } \\
\text { kpi }_{j k} \text { of enterprise } j\end{array}$ \\
\hline $\mathrm{n}$ & $\begin{array}{l}\text { Identifier number for the alternative of solution selected to solve the SAM, using the } \\
\text { output of CS1 }\left(\mathrm{SAM}^{\mathrm{CS}} \mathrm{i}_{-}\right), \mathrm{n}=[1,2, \ldots, \mathrm{n}]\end{array}$ \\
\hline $\mathrm{m}$ & Identifier number for the iteration, where $\mathrm{m}=\mathrm{n}$ \\
\hline m_max & $\begin{array}{l}\text { Maximum number of iterations consented by all the } \mathrm{CN} \text { enterprises to negotiate the } \\
\text { alternatives generated }\end{array}$ \\
\hline SAM ${ }^{\mathrm{NCS}} \_\mathrm{i}$ & SAM calculated in enterprise i given that NCS is applied \\
\hline SAM ${ }^{\mathrm{CS} 1 \_\mathrm{i}}$ & SAM calculated in enterprise i given that CS1 is applied \\
\hline SAM ${ }^{\text {CS1_i_n }}$ & $\begin{array}{l}\text { SAM calculated in enterprise i given that CS1 is applied and considering the solution of } \\
\text { alternative } \mathrm{n} \mathrm{u}_{-} \mathrm{str}_{\mathrm{is}}^{\mathrm{CS} 1 \_\mathrm{n}}, \mathrm{ti}_{\mathrm{i}} \mathrm{str}_{\mathrm{is}} \mathrm{CS}{ }_{\mathrm{n}} \mathrm{n}\end{array}$ \\
\hline $\mathrm{kpi}_{\text {net }}^{\mathrm{NCS}}$ & Network performance indicator value $\mathrm{kpi}_{\text {net }}$ given the NCS solution \\
\hline $\mathrm{kpi}_{\mathrm{i}}^{\mathrm{NCS}}$ & Enterprise i performance indicator value $\left(\mathrm{kpi}_{\mathrm{i}}\right)$ given the NCS solution \\
\hline u_str ${ }_{\text {is }}^{\mathrm{NCS}}$ & Enterprise $\mathrm{i}$ units of strategy value ( $\mathrm{u}_{\text {_str }}$ is $)$ given the NCS solution \\
\hline ti_str ${ }_{\text {is }}^{\mathrm{NCS}}$ & Enterprise i start time value of $\operatorname{str}_{\text {is }}\left(\mathrm{ti}_{\mathrm{S}} \mathrm{str}_{\mathrm{is}}\right)$ given the NCS solution \\
\hline $\mathrm{kpi}_{\mathrm{i}}^{\mathrm{CS} 1 \_\mathrm{n}}$ & Enterprise i performance indicator value $\left(\mathrm{kpi}_{\mathrm{i}}\right)$ given the CS1 solution of alternative $\mathrm{n}$ \\
\hline u_str ${ }_{\text {is }}^{C S 1 \_n}$ & Enterprise $\mathrm{i}$ units of strategy value $\left(\mathrm{u} \_\mathrm{str}_{\mathrm{is}}\right.$ ) given the CS1 solution of alternative $\mathrm{n}$ \\
\hline ti_str ${ }_{\text {is }}^{\text {CS1_n }}$ & Enterprise i start time value of $\operatorname{str}_{\text {is }}\left(\mathrm{ti}_{-} \mathrm{str}_{\mathrm{is}}\right)$ given the CS1 solution of alternative $\mathrm{n}$ \\
\hline$\Delta \mathrm{kpi}_{\mathrm{i}}^{\mathrm{CS} 1 \_\mathrm{j} \_\mathrm{n}}$ & $\begin{array}{l}\mathrm{kpi}_{\mathrm{i}} \text { increase resulting from the influences that strategies activated in enterprise } \mathrm{j} \text { exert in } \\
\text { enterprise } \mathrm{i} \text { given } \mathrm{CS} 1 \text { solution }\left(\mathrm{u}_{-} \mathrm{str}_{\mathrm{js}}^{\mathrm{CS} 1 \_\mathrm{n}}, \mathrm{ti}_{-} \mathrm{str}_{\mathrm{j}}^{\mathrm{CS}}{ }_{-} \mathrm{n}\right) \text { of alternative } \mathrm{n}\end{array}$ \\
\hline $\mathrm{kpi}_{\mathrm{i}}^{\mathrm{CS} 1 \_\mathrm{n}} \_$real & 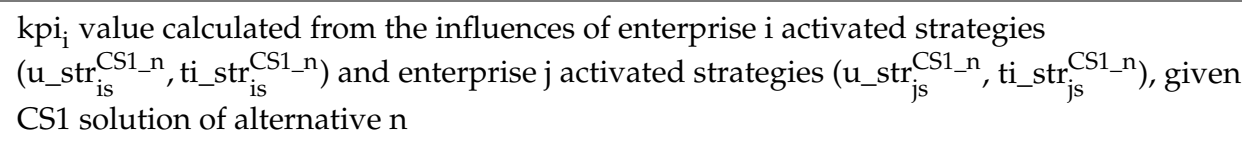 \\
\hline $\mathrm{kpi}_{\text {net }}^{\mathrm{CS} 1 \_\mathrm{n}}$ & Network performance indicator value given CS1 solution of alternative $\mathrm{n}$ \\
\hline$C C x^{i}$ & Enterprise i criterion choice $x$ \\
\hline $\mathrm{CCx}$ & Enterprise $\mathrm{j}$ criterion choice $\mathrm{x}$ \\
\hline$\Delta^{\min } \mathrm{kpi}_{\mathrm{i}}^{\mathrm{CS} 1 \_\mathrm{j}}$ & $\begin{array}{l}\mathrm{kpi}_{\mathrm{i}} \text { minimum increase reflecting the influences of strategies activated in enterprise } \mathrm{j} \text {, given } \\
\text { the CS1 solution computed by enterprise } \mathrm{i}\end{array}$ \\
\hline min_kpi ${ }_{i}^{\mathrm{CS}} \_$real & $\mathrm{kpi}_{\mathrm{i}}^{\mathrm{CS} 1}$ _real minimum value identified by Enterprise $\mathrm{i}$, given the CS1 solution \\
\hline$\alpha$ & $\begin{array}{l}1 \text { when the } C C x^{i} \text { is fulfilled } \\
0 \text { when the } C C x^{i} \text { is not fulfilled }\end{array}$ \\
\hline$\beta$ & $\begin{array}{l}1 \text { when the } C C x^{j} \text { is fulfilled } \\
0 \text { when the } C C x^{j} \text { is not fulfilled }\end{array}$ \\
\hline
\end{tabular}

STEP1. Compute the SAM given the NCS $\left(\mathrm{SAM}^{\mathrm{NCS}}{ }_{-} \mathrm{i}\right)$

Each $\mathrm{CN}$ enterprise computes the SAM by only considering the data of their performance indicators and strategies, calculating the

- Performance indicator value at enterprise level

Enterprise i: $\mathrm{kpi}_{\mathrm{i}}^{\mathrm{NCS}}$ 


\section{Enterprise $\mathrm{j}: \mathrm{kpi}_{\mathrm{j}} \mathrm{NCS}$}

- Decision variables value

Enterprise i: activated strategy units $\mathrm{u}_{-} \mathrm{str}_{\text {is }}^{\mathrm{NCS}}$, and activation start time ti_str ${ }_{\text {is }}^{\mathrm{NCS}}$

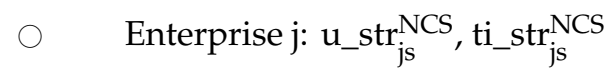

Network performance is computed considering the sum of the performance indicators of each enterprise $\mathrm{kpi}_{\text {net }}^{\mathrm{NCS}}=\mathrm{kpi}_{\mathrm{i}}^{\mathrm{NCS}}+\mathrm{kpi}_{\mathrm{j}}^{\mathrm{NCS}}$.

STEP 2. Interchanged performance indicators data $\left(\mathrm{kpi}_{\mathrm{ik}}\right)$

The data regarding the performance indicators defined in enterprise $\mathrm{i}\left(\mathrm{kpi}_{\mathrm{ik}}\right)$ is shared with enterprise $\mathrm{j}$, and viceversa.

STEP 3. Estimate influence values (val_str is_ $_{\text {kpik }}$ ).

Enterprise $\mathrm{i}$ determines the intra- and inter-enterprise influence values val_str ${ }_{\mathrm{is} \_} \mathrm{kpi}_{\mathrm{ik}}$

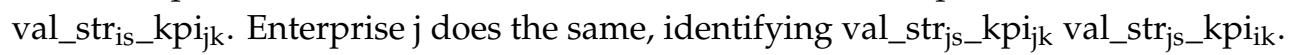

STEP 4. Compute the SAM given the CS1 (SAM ${ }^{\mathrm{CS} 1 \_\mathrm{i}}$ )

Each CN partner computes its own SAM ${ }^{\mathrm{CS} 1 \_\mathrm{i}}$ using the data exchanged. The calculation of the $\mathrm{SAM}^{\mathrm{CS} 1 \_\mathrm{i}}$ generates optimal and near optimal solutions. Each solution provided by SAM ${ }^{\mathrm{CS} 1 \_\mathrm{i}}$ will $^{\mathrm{i}}$ be considered as an alternative, $\mathrm{n}$. There are as many alternatives as solutions. $\mathrm{n}$ is the maximum number of alternatives of solution. The solution of the SAM ${ }^{\mathrm{CS} 1}{ }_{-}^{\mathrm{i}}$ corresponding to the alternative $\mathrm{n}$ is obtained, including

- Values of the performance indicators at enterprise level

$\begin{array}{ll} & \text { Enterprise } \mathrm{i}: \mathrm{kpi}_{\mathrm{i}}{ }_{\mathrm{CS}} \mathrm{n} \\ & \text { Enterprise } \mathrm{j}: \mathrm{kpi}_{\mathrm{j}}{ }_{\mathrm{C}}{ }_{-} \mathrm{n}\end{array}$

- Values of the decision variables

Enterprise $\mathrm{i}: \mathrm{u}_{\mathrm{str}} \mathrm{CS}_{\mathrm{is}}{ }_{\mathrm{n}}, \mathrm{ti}_{\mathrm{str}}{ }_{\text {is }} \mathrm{CS}_{\mathrm{n}}$

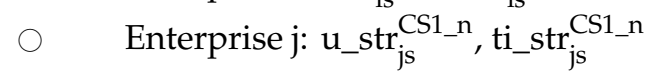

- $\quad \mathrm{kpi}_{\mathrm{i}}$ is increased or decreased $\left(\Delta \mathrm{kpi}_{i}{ }^{\mathrm{CS} 1 \_j \_n}\right)$ given the strategies activated in enterprise $\mathrm{j}\left(\mathrm{u} \_s t r_{\mathrm{js}}^{\mathrm{CS} 1 \_n}\right.$, ti_str ${ }_{j s}^{C S 1 \_n}$ )

- $\quad \mathrm{kpi}_{\mathrm{j}}$ is increased or decreased $\left(\Delta \mathrm{kpi}_{\mathrm{j}}^{\mathrm{CS} 1 \_\mathrm{i} \_\mathrm{n}}\right)$ given the strategies activated in enterprise $\mathrm{i} \mathrm{u}_{-} \operatorname{str}_{\text {is }}^{\mathrm{CS} 1 \_n}$, ti_str ${ }_{\text {is }}^{\mathrm{CS}} \_\mathrm{n}$. Thus,

Enterprise $\mathrm{i}: \mathrm{kpi}_{\mathrm{i}}^{\mathrm{CS} 1 \_\mathrm{n}}{ }_{-} \mathrm{real}=\mathrm{kpi}_{\mathrm{i}}^{\mathrm{CS} 1 \_\mathrm{n}}+\Delta \mathrm{kpi}_{\mathrm{i}}^{\mathrm{CS} 1 \_\mathrm{j} \_\mathrm{n}}$

$\bigcirc \quad$ Enterprise $\mathrm{j}$ : the $\mathrm{kpi}_{\mathrm{j}}^{\mathrm{CS} 1 \_\mathrm{n}}{ }_{-}$real $=\mathrm{kpi}_{\mathrm{j}}^{\mathrm{CS} 1 \_\mathrm{n}}+\Delta \mathrm{kpi}_{\mathrm{j}}^{\mathrm{CS} 1 \_\mathrm{i} \_\mathrm{n}}$

Network performance is computed considering the sum of the performance indicators of each enterprise $\mathrm{kpi}_{\text {net }}^{\mathrm{CS} 1 \_\mathrm{n}}=\mathrm{kpi}_{{ }_{\mathrm{i}} \mathrm{CS} 1 \_\mathrm{n}}{ }_{-}$real $+\mathrm{kpi}_{\mathrm{j}}^{\mathrm{CS} 1 \_\mathrm{n}}{ }_{-}$real.

STEP 5. Criteria choice selection $\left(C C x^{\mathrm{i}}\right)$ 
Criteria choice $\left(C C x^{i}\right)$ connects the SAM results with the enterprise objectives. In step 5 , the rules for the negotiation are determined. The $C C x^{i}$ determines how acceptable an alternative solution $\mathrm{n}$ is. Next, three examples of the CCx are given for the NP_CS1 context:

$\mathrm{CC} 1$ is the minimum increase required for the performance indicator level at enterprise i considering the impact of the strategies activated by the rest of $\mathrm{CN}$ partners (i.e., enterprise j) $\Delta^{\mathrm{min}} \mathrm{kpi}_{\mathrm{i}} \mathrm{CS}_{-} \mathrm{j}$. The difference between the $\mathrm{kpi}_{\mathrm{i}}{ }^{\mathrm{CS} 1 \_\mathrm{n}}$ and $\mathrm{kpi}_{\mathrm{i}}^{\mathrm{CS} 1 \_\mathrm{n}}$ _real is used by enterprise $\mathrm{i}$ to define the minimum increase required in its $\mathrm{kpi}_{\mathrm{i}}$, considering the activation enterprise $\mathrm{j}$ strategies $\left(\Delta^{\mathrm{min}} \mathrm{kpi}_{\mathrm{i}}{ }_{\mathrm{CS}} \mathrm{j}\right)$. Therefore,

$$
\alpha=\left\{\begin{array}{c}
1 \leftrightarrow \sum_{j} \Delta \mathrm{kpi}_{\mathrm{i}}{ }^{\mathrm{CS} 1_{j} \_\mathrm{n}} \geq \Delta^{\mathrm{min}} \mathrm{kpi}_{\mathrm{i}}{ }^{\mathrm{CS} 1_{j}} \\
0
\end{array}\right.
$$

CC2 is the minimum real value established for the performance indicators at enterprise level min_kpi ${ }_{i}^{\mathrm{CS} 1}$ _real. Considering the difference within $\mathrm{kpi}_{\mathrm{i}}^{\mathrm{NCS}}$ and $\mathrm{kpi}_{\mathrm{i}}^{\mathrm{CS1} \_\mathrm{n}}$ _real, Enterprise i determines the minimum value required in the $\mathrm{kpi}_{\mathrm{i}}\left(\mathrm{min} \_\mathrm{kpi}_{\mathrm{i}}^{\mathrm{CS} 1} \_\right.$real $)$. Therefore,

$$
\alpha=\left\{\begin{array}{c}
1 \leftrightarrow \mathrm{kpi}_{\mathrm{i}}^{\mathrm{CS} 1 \_\mathrm{n}} \_ \text {real } \geq \mathrm{min} \_\mathrm{kpi}_{\mathrm{i}}^{\mathrm{CS} 1} \_ \text {real } \\
0
\end{array}\right.
$$

CC3 is the performance indicator at the enterprise level given CS1, taking into account the impact of the strategies formulated by other $\mathrm{CN}$ enterprises, $\mathrm{kpi}_{\mathrm{i}}^{\mathrm{CS} 1 \_\mathrm{n}}{ }_{-}$real $=\mathrm{kpi}_{\mathrm{i}}^{\mathrm{CS} 1 \_\mathrm{n}}+\Delta \mathrm{kpi}_{\mathrm{i}}{ }^{\mathrm{CS} 1}{ }_{\mathrm{j} \_} \mathrm{n}$ must be higher than the performance indicator at enterprise level given the NCS, $\mathrm{kpi}_{\mathrm{i}}^{\mathrm{NCS}}$. Therefore,

$$
\alpha=\left\{\begin{array}{c}
1 \leftrightarrow \mathrm{kpi}_{\mathrm{i}}^{\mathrm{CS} 1 \_\mathrm{n}}+\Delta \mathrm{kpi}_{\mathrm{i}}^{\mathrm{CS} 1 \_j \_\mathrm{n}} \geq \mathrm{kpi}_{\mathrm{i}}^{\mathrm{NCS}} \\
0
\end{array}\right.
$$

Hereafter, an example of the CCx defined and selected by enterprises $i$ and $j$ is illustrated. The

\begin{tabular}{|c|c|c|c|c|c|c|}
\hline \multirow{4}{*}{$\begin{array}{l}\text { Minimum values } \\
\text { defined for the CC }\end{array}$} & \multicolumn{3}{|c|}{ Enterprise i } & \multicolumn{3}{|c|}{ Enterprise $\mathbf{j}$} \\
\hline & \multicolumn{2}{|l|}{$\mathbf{k p i}_{\mathbf{i}}$} & \multirow[t]{3}{*}{ stris $_{\text {is }}$} & \multicolumn{2}{|l|}{$\mathbf{k p i}_{\mathbf{j}}$} & \multirow[t]{3}{*}{$\operatorname{str}_{j s}$} \\
\hline & $\Delta^{\min } \mathrm{kpi}_{\mathrm{i}}^{\mathrm{CS} 1 \_\mathrm{j}}$ & 1.6 & & $\Delta^{\min } \mathrm{kpi}_{j}^{\mathrm{CS} 1 \_\mathrm{i}}$ & 1.5 & \\
\hline & $\min \_\mathrm{kpi}_{\mathrm{i}}^{\mathrm{CS} 1} \_$real & 5 & & $\min \_\mathrm{kpi}_{\mathrm{j}}^{\mathrm{CS} 1} \_$real & 12 & \\
\hline SAM in NCS & $\mathrm{kpi}_{\mathrm{i}}^{\mathrm{NCS}}$ & 5 & $\begin{array}{l}\text { u_str }{ }_{\text {is }}^{\mathrm{NCS}} \\
\text { ti_str }{ }_{\text {is }}^{\mathrm{NCS}}\end{array}$ & $\mathrm{kpi}_{\mathrm{j}}^{\mathrm{NCS}}$ & 12 & $\begin{array}{l}\text { u_str }{ }_{j s}^{N C S} \\
\text { ti_str }{ }_{j s}^{N C S}\end{array}$ \\
\hline \multirow{5}{*}{ SAM in CS1 } & $\mathrm{kpi}_{\mathrm{i}}^{\mathrm{CS} 1 \_\mathrm{n}}$ & 4.3 & \multirow{3}{*}{$\begin{array}{l}\text { u_str }{ }_{\text {is }}^{\mathrm{CS} 1 \_n} \\
\text { ti_str }{ }_{\text {is }}^{\mathrm{CS} 1 \_n}\end{array}$} & $\mathrm{kpi}_{\mathrm{j}}^{\mathrm{CS} 1 \_\mathrm{n}}$ & 10 & \multirow{3}{*}{$\begin{array}{l}\text { u_str }{ }_{j s}^{C S 1} n \\
\text { ti_str }{ }_{j \mathrm{js}}^{\mathrm{CS} 1 \_n}\end{array}$} \\
\hline & $\Delta \mathrm{kpi}_{\mathrm{i}}^{\mathrm{CS} 1 \_\mathrm{j} \_\mathrm{n}}$ & 1.5 & & $\Delta \mathrm{kpi}^{\mathrm{C}} \mathrm{CS}_{-}{ }_{-}^{\mathrm{i}} \_\mathrm{n}$ & 1.5 & \\
\hline & $\mathrm{kpi}_{\mathrm{i}}^{\mathrm{CS} 1 \_\mathrm{n} \text { _real }}$ & 5.8 & & $\mathrm{kpi}_{\mathrm{j}}^{\mathrm{CS} 1 \_\mathrm{n} \text { _real }}$ & 11.5 & \\
\hline & $\mathrm{kpi}_{\text {net }}^{\mathrm{NCS}}$ & 17 & & & & \\
\hline & kpi ${ }_{\text {net }}$ & 17.3 & & & & \\
\hline
\end{tabular}
fulfilment of the $C C x^{i}, \alpha=\{0,1\}$, is computed according to the following illustrative example (Table 2).

Table 2. Example of CS1 given the alternative of solution $n$.

- $\quad$ Enterprise i:

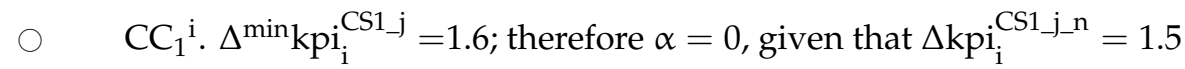

$\circ \quad \mathrm{CC}_{2}{ }^{\mathrm{i}} \cdot \min \_\mathrm{kpi}_{\mathrm{i}}^{\mathrm{CS} 1} \_$real $=5$; therefore $\alpha=1$, given that $\mathrm{kpi}_{\mathrm{i}}^{\mathrm{CS} 1 \_\mathrm{n}}$ _real $=5.8$

$\bigcirc \quad \mathrm{CC}_{3}{ }^{\mathrm{i}} \cdot \mathrm{kpi}_{\mathrm{i}}^{\mathrm{CS1} \_\mathrm{n}}$ _real $=\mathrm{kpi}_{\mathrm{i}}{ }^{\mathrm{CS} 1 \_\mathrm{n}}+\Delta \mathrm{kpi}_{\mathrm{i}}^{\mathrm{CS} 1 \_\mathrm{j} \_\mathrm{n}}=5.8$; therefore $\alpha=1$, given that $\mathrm{kpi}_{\mathrm{i}}^{\mathrm{NCS}}=5$ 
- $\quad$ Enterprise j:

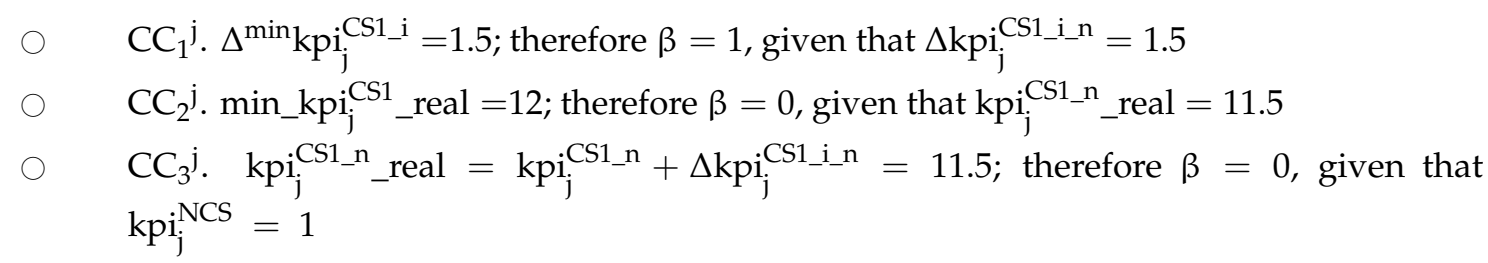

Form the previous example, it can be concluded that, although in some occasions the CCx is not met $(\alpha=0 ; \beta=0)$, the $\mathrm{kpi}_{\text {net }}^{\mathrm{CS1} \mathrm{n}}$ is achieved, due to $\mathrm{kpi}_{\text {net }}^{\mathrm{CS1} n} \geq \mathrm{kpi}_{\text {net }}^{\mathrm{NCS}}$.

STEP 6. Definition of the iterative process stopping rule

Stopping rules examples:

- Maximum amount of iterations agreed by all the CN partners (m_max)

- When kpi ${ }_{\text {net }}^{\mathrm{CS} 1 \_\mathrm{n}}>\mathrm{kpi}_{\text {net }}^{\mathrm{NCS}}$

- A value of $\mathrm{kpi}_{\text {net }}^{\mathrm{CS1} \mathrm{n}}$ is reached

- $\alpha=1$ and $\beta=1$

- $\quad \Delta \mathrm{kpi}_{\mathrm{i}}{ }^{\mathrm{CS} 1 \_\mathrm{j} \_} \mathrm{n}$ is within a lower and upper bound established by the $\mathrm{CN}$ partners

- When $\mathrm{kpi}_{\mathrm{i}}^{\mathrm{CS}}{ }_{-} \mathrm{n}$ _real is within a lower and upper bound established by the $\mathrm{CN}$ partners

STEP 7. Selection of the alternative of solution $n$

An alternative solution $n$ from $\mathrm{SAM}^{\mathrm{CS} 1_{-} \mathrm{i}}$ and $\mathrm{SAM}^{\mathrm{CS} 1_{-} \mathrm{j}}$ has to be selected. Enterprise $\mathrm{i}$ and

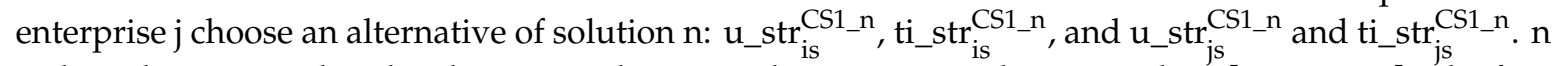
is the value assigned to the alternative chosen, and is consecutively assigned $n=[1,2, \ldots, n]$. The first selected alternative would commonly be the one that achieves the optimum value for the enterprise performance indicator, max. $\mathrm{kpi}_{\mathrm{i}}^{\mathrm{CS} 1 \_\mathrm{n}}$. The selected alternative coincides with the first iteration of the NP_CS1; thus, $\mathrm{n}=\mathrm{m}$.

STEP 8. Compute the SAM ${ }^{\mathrm{CS} 1 \_\mathrm{i}}$ considering the results of the selected alternative (n)

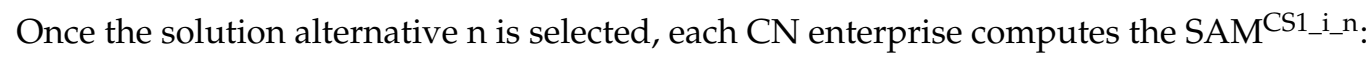

- Enterprise i computes the SAM ${ }^{\mathrm{CS} 1 \_\mathrm{i} \_n}$ considering the solution alternative selected, $\mathrm{u}_{-} \mathrm{str}_{\mathrm{is}}^{\mathrm{CS}}{ }_{-} \mathrm{n}$, $\mathrm{ti}_{-} \mathrm{str}_{\mathrm{is}}^{\mathrm{CS}} \mathrm{n}^{\mathrm{n}}$, and obtains the values for $\mathrm{kpi}_{\mathrm{i}}^{\mathrm{CS}}{ }_{-} \mathrm{n}$ and $\Delta \mathrm{kpi}_{\mathrm{j}}{ }_{\mathrm{CS}}{ }_{-} \mathrm{i}_{-} \mathrm{n}$

- Enterprise j computes the $\mathrm{SAM}^{\mathrm{CS} 1 \_j \_n}$ considering the solution alternative selected, $\mathrm{u}_{-} \mathrm{str}_{\mathrm{j} \mathrm{s}}^{\mathrm{CS}}{ }^{\mathrm{n} n}$, $\mathrm{ti}_{-} \mathrm{str}_{\mathrm{js}}^{\mathrm{CS}} \mathrm{B} \mathrm{n}$, and obtains the values for $\mathrm{kpi}_{\mathrm{j}}^{\mathrm{CS}}{ }_{-} \mathrm{n}$ and $\Delta \mathrm{kpi}_{\mathrm{i}}^{\mathrm{CS}}{ }_{-} \mathrm{j}_{-} \mathrm{n}$

STEP 9. Share the increase values proposed by the enterprises $\Delta \mathrm{kpi}_{\mathrm{i}}{ }^{\mathrm{CS}}{ }_{-} \_\mathrm{n}$.

The $\mathrm{kpi}_{\mathrm{i}}$ increase value (defined by Enterprise i) is computed considering the influences exerted by the strategies activated in enterprise $\mathrm{j}$, given the CS1:

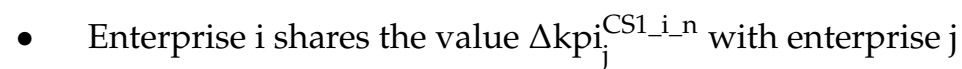

- Enterprise $\mathrm{j}$ shares the value $\Delta \mathrm{kpi}_{\mathrm{i}}{ }^{\mathrm{CS}}{ }_{-} \mathrm{j} \mathrm{n}$ with enterprise $\mathrm{i}$

For solution alternative $\mathrm{n}$ (iteration $\mathrm{m}$ ), depending on the strategies activated in enterprise $\mathrm{i}$

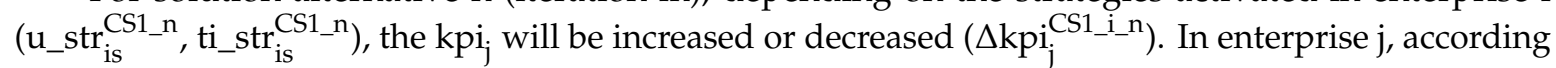

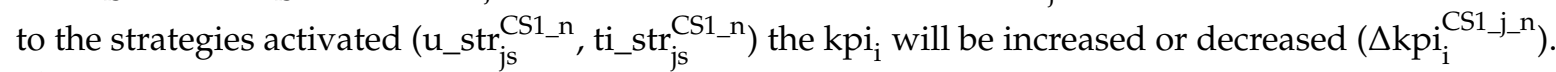
Thus, 
- $\quad$ Enterprise i: $\mathrm{kpi}_{\mathrm{i}}^{\mathrm{CS} 1 \_\mathrm{n}} \_$real $=\mathrm{kpi}_{\mathrm{i}}^{\mathrm{CS} 1 \_\mathrm{n}}+\Delta \mathrm{kpi}_{\mathrm{i}}^{\mathrm{CS} 1 \_\mathrm{j} \_\mathrm{n}}$

- $\quad$ Enterprise $\mathrm{j}: \mathrm{kpi}_{\mathrm{j}}^{\mathrm{CS} 1 \_\mathrm{n}} \_$real $=\mathrm{kpi}_{\mathrm{j}}^{\mathrm{CS} 1 \_\mathrm{n}}+\Delta \mathrm{kpi}_{\mathrm{j}}^{\mathrm{CS} 1 \_\mathrm{i} \_\mathrm{n}}$

Step 9.1. If Enterprise i: $\alpha=1$ and Enterprise $\mathrm{j}: \beta=1$ the negotiation is finished and a collaborative

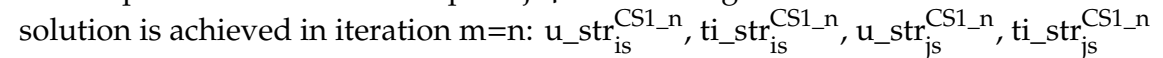

Step 9.2. If Enterprise i: $\alpha=0$ and Enterprise $\mathrm{j}: \beta=0$ the negotiation is finished and a non-collaborative

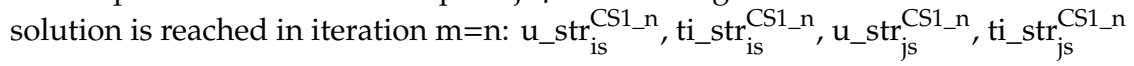

Step 9.3. If Enterprise $\mathrm{i}: \alpha=0$ and Enterprise $\mathrm{j}: \beta=1$ or Enterprise i: $\alpha=1$ and Enterprise j: $\beta=0$

The iterative process stopping rule is not met and steps 7, 8 and 9 have to be repeated

Step 9.4. If Enterprise i: $\alpha=0$ and Enterprise $\mathrm{j}: \beta=1$ or

Enterprise i: $\alpha=1$ and Enterprise j: $\beta=0$

The iterative process stopping rule is met the negotiation is finished and a non-ollaborative

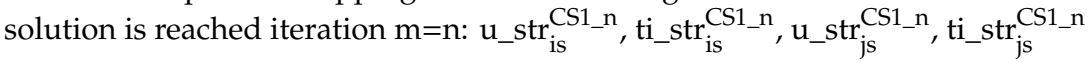

\subsection{Negotiation Process CS2 (NP_CS2)}

The negotiation process described to deal with the CS2 is depicted in Figure 6. NP_CS2 enables

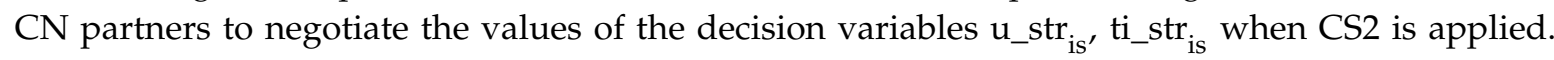
Table 3 lists the parameters used in the NP_CS2. The steps to follow in the NP-CS2 are detailed in the following sections.

Table 3. NP_CS2 parameters.

\begin{tabular}{|c|c|}
\hline Notation & Definition \\
\hline $\mathrm{kpi}_{\mathrm{ik}}$ & Enterprise i performance indicators \\
\hline val_str ${ }_{\mathrm{is}-} \mathrm{kpi}_{\mathrm{ik}}$ & $\begin{array}{l}\text { Intra-enterprise influence values estimated. Impact value that } \operatorname{str}_{\mathrm{is}} \text { of enterprise } \mathrm{i} \text { has on } \\
\mathrm{kpi}_{\mathrm{ik}} \text { of enterprise } \mathrm{i}\end{array}$ \\
\hline val_stris_kpi ${ }_{j k}$ & $\begin{array}{l}\text { Inter-enterprise influence values estimated. Impact value that } s \mathrm{r}_{\mathrm{is}} \text { of enterprise } \mathrm{i} \text { has on } \\
\mathrm{kpi}_{\mathrm{jk}} \text { of enterprise } \mathrm{j}\end{array}$ \\
\hline $\mathrm{n}$ & $\begin{array}{l}\text { Identifier number for the alternative of solution selected to solve the SAM, using the } \\
\text { output of CS2 }\left(\mathrm{SAM}^{\mathrm{CS} 2}{ }^{\mathrm{i}}\right), \mathrm{n}=[1,2, \ldots, \mathrm{n}]\end{array}$ \\
\hline $\mathrm{m}$ & Identifier number for the iteration, where $\mathrm{m}=\mathrm{n}$ \\
\hline m_max & $\begin{array}{l}\text { Maximum number of iterations consented by all the } \mathrm{CN} \text { enterprises to negotiate the } \\
\text { alternatives generated }\end{array}$ \\
\hline $\mathrm{SAM}^{\mathrm{NCS}} \mathrm{i}$ & SAM calculated in enterprise i given that NCS is applied \\
\hline SAM ${ }^{\text {CS2_i }}$ & SAM calculated in enterprise $\mathrm{i}$ given that CS2 is applied \\
\hline SAM ${ }^{\text {CS2_i_n }}$ & 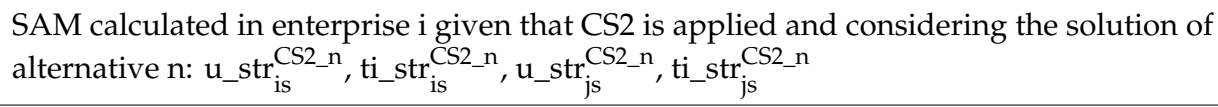 \\
\hline $\mathrm{kpi}_{\text {net }}^{\mathrm{NCS}}$ & Network performance indicator value $\mathrm{kpi}_{\text {net }}$ given the NCS solution \\
\hline $\mathrm{kpi}_{\mathrm{i}}^{\mathrm{NCS}}$ & Enterprise i performance indicator value $\left(\mathrm{kpi}_{\mathrm{i}}\right)$ given the NCS solution \\
\hline u_str ${ }_{\text {is }}^{\mathrm{NCS}}$ & Enterprise $i$ units of strategy value $\left(u_{\text {_sstr }}\right.$ is $)$ given the NCS solution \\
\hline ti_str ${ }_{\text {is }}^{\mathrm{NCS}}$ & Enterprise i start time value of stris $_{\text {is }}\left(\mathrm{ti}_{\text {_stris }}\right.$ ) given the NCS solution \\
\hline $\mathrm{kpi}_{\text {net }}^{\mathrm{CS} 2}$ & Network performance indicator value $\mathrm{kpi}_{\text {net }}$ given the CS2 solution \\
\hline $\mathrm{kpi}_{\mathrm{i}}^{\mathrm{CS} 2}$ & Enterprise i performance indicator value $\left(\mathrm{kpi}_{\mathrm{i}}\right)$ given the CS2 solution of alternative $\mathrm{n}$ \\
\hline u_str ${ }_{\text {is }}^{C S 2}$ & Enterprise $\mathrm{i}$ units of strategy value ( $\mathrm{u} \_\mathrm{str}_{\mathrm{is}}$ ) given the CS2 solution of alternative $\mathrm{n}$ \\
\hline ti_str ${ }_{\text {is }}^{\text {CS2 }}$ & Enterprise i start time value of str $_{\text {is }}$ ( ti_str $_{\text {is }}$ ) given the CS2 solution of alternative $n$ \\
\hline
\end{tabular}


Table 3. Cont.

\begin{tabular}{|c|c|}
\hline Notation & Definition \\
\hline $\mathrm{kpi}_{\mathrm{i}}^{\mathrm{CS} 2 \_\mathrm{i} \_\mathrm{n}}$ & $\begin{array}{l}\text { Enterprise i performance indicator value } \mathrm{kpi}_{\mathrm{i}} \text { considering the influences of all the } \\
\text { strategies activated in each CN enterprise (enterprise } \mathrm{i} \text {; enterprise } \mathrm{j} \text { ), obtained by } \\
\text { enterprise } \mathrm{i} \text { when } \mathrm{SAM} \text { is computed given the CS2 }\left(\mathrm{SAM}^{\mathrm{CS} 2}{ }_{-}^{\mathrm{i}}\right) \text { of alternative } \mathrm{n}\end{array}$ \\
\hline $\mathrm{kpi}_{\mathrm{j}}^{\mathrm{CS} 2 \_\mathrm{i} \_\mathrm{n}}$ & $\begin{array}{l}\text { Enterprise } j \text { performance indicator value } \mathrm{kpi}_{\mathrm{j}} \text { considering the influences of all the } \\
\text { strategies activated in each } \mathrm{CN} \text { enterprise (enterprise } \mathrm{i}_{\text {; }} \text { enterprise } \mathrm{j} \text { ), obtained by } \\
\text { enterprise } \mathrm{j} \text { when SAM is computed given the CS2 (SAM }{ }^{\mathrm{CS} 2}{ }_{-} \text {) of alternative } n\end{array}$ \\
\hline u_str ${ }_{\text {is }}^{C S 2 \_i \_n ~}$ & $\begin{array}{l}\text { Value of the units of strategy } \operatorname{str}_{\text {is }} \text { to be activated }\left(u_{-} \operatorname{str}_{i s}\right) \text { in enterprise } i \text {; obtained by } \\
\text { enterprise } i \text { when SAM is computed given the CS2 }\left(S A M^{\mathrm{CS} 2}{ }_{-} \mathrm{i}\right) \text {, corresponding to the } \\
\text { alternative } \mathrm{n}\end{array}$ \\
\hline ti_str ${ }_{\text {is }}^{\text {CS2_i_n }}$ & $\begin{array}{l}\text { Value of the initial time of activation of strategy } \operatorname{str}_{\text {is }}\left(\operatorname{ti}_{-} \operatorname{str}_{\text {is }}\right) \text { formulated in enterprise } \mathrm{i} \text {; } \\
\text { and obtained by enterprise } \mathrm{i} \text { when SAM is computed given the CS2 }\left(\mathrm{SAM}^{\mathrm{CS} 2}{ }_{-}{ }\right) \text {, } \\
\text { corresponding to the alternative } \mathrm{n}\end{array}$ \\
\hline u_str ${ }_{j s}^{C S 2 \_i \_n}$ & $\begin{array}{l}\text { Value of the units of strategy } \operatorname{str}_{j \mathrm{~s}} \text { to be activated }\left(\mathrm{u}_{\mathrm{s}} \mathrm{str}_{\mathrm{j}}\right) \text { in enterprise } \mathrm{j} \text {; and obtained by } \\
\left.\text { Enterprise } \mathrm{i} \text { when SAM is computed given the CS2 (SAM }{ }^{\mathrm{CS}}{ }_{-} \mathrm{i}\right) \text {, corresponding to the } \\
\text { alternative } \mathrm{n}\end{array}$ \\
\hline ti_str ${ }_{j \mathrm{j}}^{\mathrm{CS} 2 \_\mathrm{i} \_n}$ & $\begin{array}{l}\text { Value of the initial time of activation of } \operatorname{strategy~} \operatorname{str}_{\mathrm{js}}\left(\mathrm{ti}_{\mathrm{i}} \mathrm{str} \mathrm{j}_{\mathrm{j}}\right) \text { formulated in enterprise } \mathrm{i} \text {; } \\
\text { and obtained by enterprise } \mathrm{i} \text { when } \mathrm{SAM} \text { is computed given the CS2 }\left(\mathrm{SAM}^{\mathrm{CS} 2}{ }^{\mathrm{i}}\right) \text {, } \\
\text { corresponding to the alternative } \mathrm{n}\end{array}$ \\
\hline $\mathrm{kpi}_{\text {net }}^{\mathrm{CS} 2 \text { i_n }}$ & $\begin{array}{l}\text { Value of the kpi }{ }_{\text {net }} \text { obtained by enterprise } \mathrm{i} \text { when SAM is computed given the CS2 } \\
\left(\mathrm{SAM}^{\mathrm{CS} 2}{ }_{-} \mathrm{i}\right) \text {, corresponding to the alternative } \mathrm{n}\end{array}$ \\
\hline 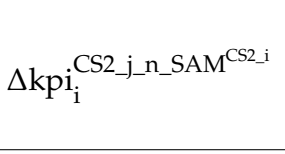 & 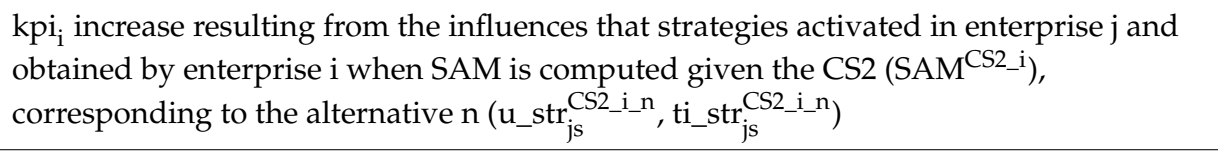 \\
\hline 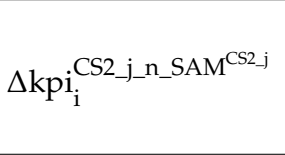 & 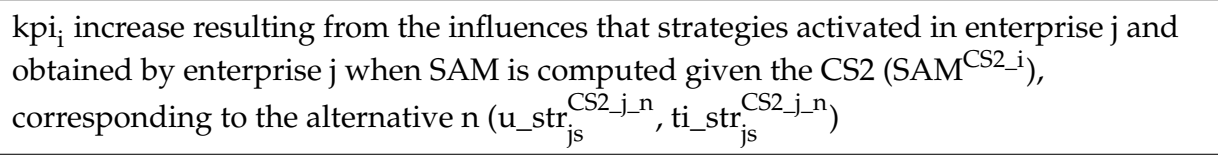 \\
\hline$C C x^{i}$ & Enterprise $\mathrm{i}$ criterion choice $\mathrm{x}$ \\
\hline$C C x^{j}$ & Enterprise $\mathrm{j}$ criterion choice $\mathrm{x}$ \\
\hline$\Delta^{\min } \mathrm{kpi}_{\mathrm{i}}^{\mathrm{CS} 2 \_\mathrm{j}}$ & $\begin{array}{l}\mathrm{kpi}_{\mathrm{i}} \text { minimum increase reflecting the influences of strategies activated in enterprise } \mathrm{j} \text {, } \\
\text { given the CS2 solution defined by Enterprise i }\end{array}$ \\
\hline$\alpha^{\mathrm{CS} 2 \_\mathrm{i} \_n}$ & 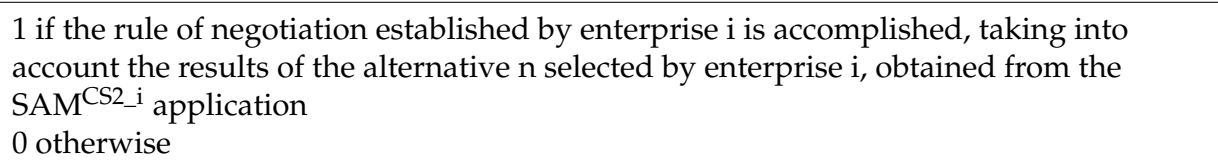 \\
\hline$\alpha^{\mathrm{CS} 2 \_j \_n}$ & $\begin{array}{l}1 \text { if the rule of negotiation established by enterprise } i \text { is accomplished, taking into } \\
\text { account the results of the alternative } n \text { selected by enterprise } j \text {, obtained from the } \\
\text { SAM }{ }^{C S 2} \mathrm{j} \text { application } \\
0 \text { otherwise }\end{array}$ \\
\hline$\beta^{\mathrm{CS} 2 \_\mathrm{i} \_n}$ & $\begin{array}{l}1 \text { if the rule of negotiation established by enterprise } \mathrm{j} \text { is accomplished, taking into account } \\
\text { the results of the alternative } n \text { selected by enterprise } \mathrm{i} \text {, obtained from the SAM }{ }^{\mathrm{CS} 2} \mathrm{i} \\
\text { application } \\
0 \text { otherwise }\end{array}$ \\
\hline$\beta^{\mathrm{CS} 2 \_j \_n}$ & $\begin{array}{l}1 \text { if the rule of negotiation established by enterprise } j \text { is accomplished, taking into account } \\
\text { the results of the alternative } n \text { selected by enterprise } j \text { obtained from the SAM }{ }^{\mathrm{CS}}{ }_{-} j \\
\text { application } \\
0 \text { otherwise }\end{array}$ \\
\hline
\end{tabular}


STEP 1. Compute the SAM in the NCS (SAM $\left.{ }^{\text {NCS }-i)}\right)$.

Each $\mathrm{CN}$ enterprise computes the SAM by only considering the data of their performance indicators and strategies, calculating the

- Performance indicator value at enterprise level

Enterprise i: $\mathrm{kpi}_{\mathrm{i}}^{\mathrm{NCS}}$

Enterprise $\mathrm{j}: \mathrm{kpi}_{\mathrm{j}}^{\mathrm{NCS}}$

- Decision variables value

Enterprise i: activated strategy units $\mathrm{u}_{-} \mathrm{str}_{\mathrm{is}}^{\mathrm{NCS}}$, and activation start time ti_str ${ }_{\text {is }}^{\mathrm{NCS}}$

Enterprise j: $u_{-}$str $_{\mathrm{js}}^{\mathrm{NCS}}$, ti_str $\mathrm{js}_{\mathrm{N}}^{\mathrm{NCS}}$

Network performance is computed considering the sum of the performance indicators of each enterprise, $\mathrm{kpi}_{\text {net }}^{\mathrm{NCS}}=\mathrm{kpi}_{\mathrm{i}}^{\mathrm{NCS}}+\mathrm{kpi}_{\mathrm{j}}^{\mathrm{NCS}}$.

STEP 2. Performance indicators parameters and strategies parameters exchanged

The data regarding the performance indicators and strategies of enterprise $\mathrm{i}\left(\mathrm{kpi}_{\mathrm{ik}}\right)$ is shared with enterprise $\mathrm{j}$, and viceversa. As regards the performance indicators:

- Enterprise i interchanges data of its performance indicators with enterprise $\mathrm{j}$, this is $\mathrm{kpi}_{\mathrm{ik}}, \mathrm{kpi}_{\mathrm{ik} \_} \mathrm{min}$, Threshold_kpi $i_{i k}$ and $\mathrm{w}_{\mathrm{ik}}$.

- Enterprise jinterchanges data of its performance indicators with enterprise $\mathrm{i}$, this is $\mathrm{kpi}_{\mathrm{jk}}, \mathrm{kpi}_{\mathrm{jk} \_} \mathrm{min}$, Threshold_kpi $\mathrm{j}_{\mathrm{jk}}$ and $\mathrm{w}_{\mathrm{jk}}$,

The codes assigned to each strategy are shared, without giving any information about the strategy description. The parameters associated to the strategies are exchanged, in order to enable each enterprise to compute the SAM ${ }^{\mathrm{CS} 2}$

- Enterprise i: shares number of strategies and its codification and the parameters that characterize

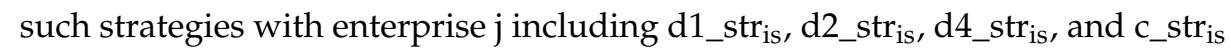

- Enterprise j: shares number of strategies and its codification and the parameters that characterize such strategies with enterprise $i$, including $d_{1 \_} s \operatorname{tr}_{j \mathrm{j}}, d_{2 \_} s \operatorname{tr}_{j \mathrm{j}}, d_{4 \_} s \operatorname{tr}_{j \mathrm{j}}$, and $\mathrm{c}_{-} \operatorname{str}_{j \mathrm{~s}}$ The value for the budget is also shared among the enterprises

- Enterprise i: shares the budget value $\left(b_{i}\right)$ with enterprise $j$

- Enterprise $j$ : shares the budget value $\left(b_{j}\right)$ with enterprise $i$

In order to maintain confidentially with the shared parameter values, parameters of cost and budget can be pre-processed and assign proportional values one another.

STEP 3. Estimate influence values (val_str ${ }_{i s \_} \mathrm{kpi}_{\mathrm{ik}}$ )

Enterprise i determines the intra and inter-enterprise influence values val_str ${ }_{i s}{ }_{k} \mathrm{kpi}_{\mathrm{ik}} \mathrm{val} \_s t r_{\mathrm{is} \_} \mathrm{kpi}_{\mathrm{jk}}$.

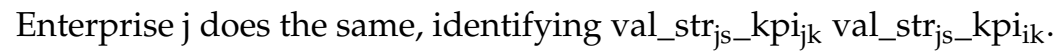

STEP 4. Interchange influence values (val_str ${ }_{\text {is_- }} \mathrm{kpi}_{\mathrm{ik}}$ )

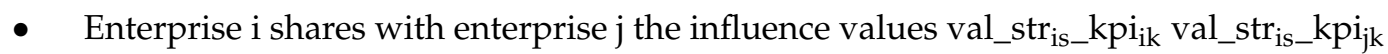

- Enterprise j shares with enterprise $i$ the influence values val_strjs_kpijk val_str ${ }_{j s \_} k i_{i k}$ 


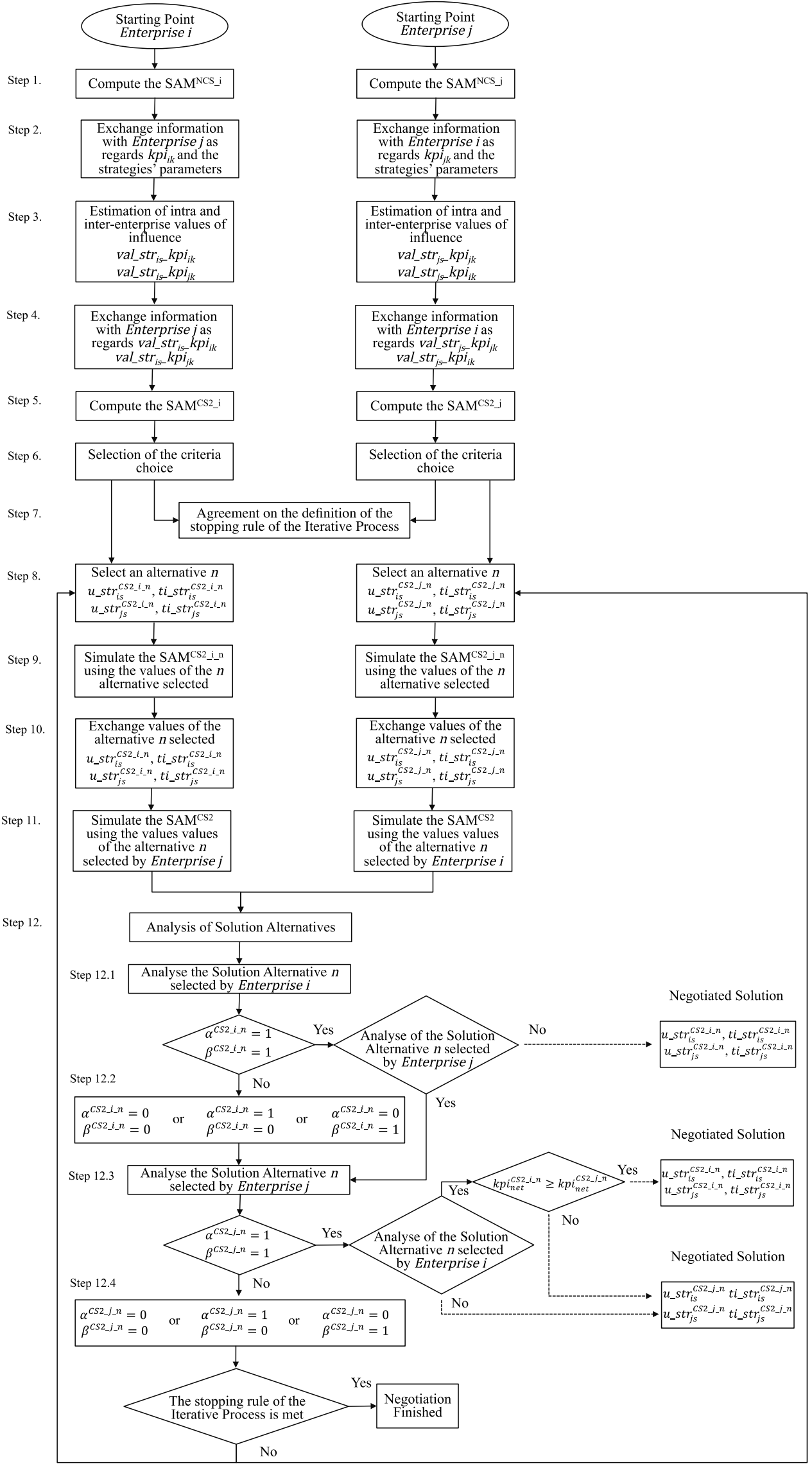

Figure 6. Negotiation Process CS2. 
STEP 5. Compute the SAM given the CS2 $\left(\mathrm{SAM}^{\mathrm{CS} 2 \_\mathrm{i}}\right)$

Each $\mathrm{CN}$ partner computes its own model, $\mathrm{SAM}^{\mathrm{CS} 2 \_\mathrm{i}}$ and $\mathrm{SAM}^{\mathrm{CS} 2} \mathrm{j}_{\mathrm{j}}$, using the data exchanged and estimated. All the $\mathrm{CN}$ partners have the same input data; therefore, the solution of the $\mathrm{SAM}^{\mathrm{CS} 2}{ }^{\mathrm{i}}$ and $\mathrm{SAM}^{\mathrm{CS} 2}{ }_{-} \mathrm{j}$ is the same in enterprise $\mathrm{i}$ and $\mathrm{j}\left(\mathrm{u} \_\mathrm{str}_{\mathrm{is}}^{\mathrm{CS} 2}, \mathrm{ti}_{-} \mathrm{str}_{\mathrm{is}}^{\mathrm{CS} 2}, \mathrm{u}_{-} \mathrm{str}_{\mathrm{js}}^{\mathrm{CS} 2}, \mathrm{ti}_{-} \mathrm{str}_{\mathrm{js}}^{\mathrm{CS} 2}\right)$. From these results, the performance indicators at enterprise and network level are computed. Obtaining,

- Performance indicator value at network level: $\mathrm{kpi}_{\text {net }}^{\mathrm{CS} 2}$

- Performances indicator value at enterprise level: $\mathrm{kpi}_{\mathrm{i}}^{\mathrm{CS} 2}$ and $\mathrm{kpi}_{\mathrm{j}}^{\mathrm{CS} 2}$

- Decision variables values: $\mathrm{u}_{-} \mathrm{str}_{\mathrm{is}}^{\mathrm{CS} 2}, \mathrm{ti} \mathrm{str}_{\mathrm{is}}^{\mathrm{CS} 2}, \mathrm{u}_{-} \mathrm{str}_{\mathrm{js}}^{\mathrm{CS} 2}, \mathrm{ti} \mathrm{str}_{\mathrm{js}}^{\mathrm{CS} 2}$

The calculation of SAM ${ }^{\mathrm{CS} 2}$ in each of the enterprises result on a set of solutions, from which one is optimal and rest are considered good enough and near optimal. Each solution provided by SAM ${ }^{\mathrm{CS} 2}$ is set as an alternative, being as much alternatives as solutions. $\mathrm{n}$ is the maximum number of solution alternatives. The solution of the $\mathrm{SAM}^{\mathrm{CS} 2}$ corresponding to the alternative $\mathrm{n}$ is obtained:

- Performance indicator value at network level:

Enterprise i: $\mathrm{kpi}_{\text {net }}^{\mathrm{C}} \mathrm{CS} \_\mathrm{i} \mathrm{n}$

Enterprise j: $\mathrm{kpi}_{\text {net }}^{\mathrm{CS} 2 \mathrm{j} \_n}$

- Performance indicators values at enterprise level

Enterprise i: $\mathrm{kpi}_{\mathrm{i}}^{\mathrm{CS} 2 \mathrm{i}_{-} \mathrm{n}}$ and $\mathrm{kpi}_{\mathrm{j}}^{\mathrm{CS} 2{ }_{-} \mathrm{i} \mathrm{n}}$

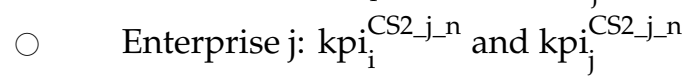

- Values of the decision variables

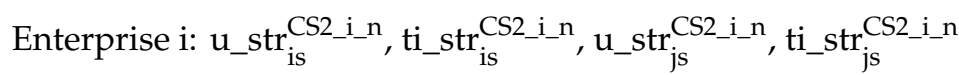

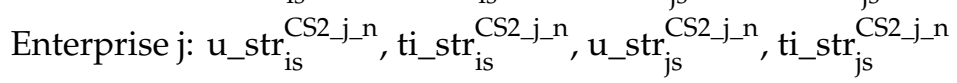

STEP 6. Criteria choice selection $\left(C C x^{\mathrm{i}}\right)$

Criteria choice $\left(C C x^{i}\right)$ connects the SAM results with the enterprise objectives. Rules for the negotiation are determined. The $C C x^{i}$ determines how acceptable an alternative solution $n$ is. Next, three examples of the CCx are given for the NP_CS2 context:

CC1. Minimum increase required for the performance indicator level at enterprise $\mathrm{i}\left(\mathrm{kpi}_{\mathrm{i}}\right)$ considering the impact of the strategies activated by the rest of $\mathrm{CN}$ partners $\left(\Delta^{\mathrm{min}} \mathrm{kpi}_{\mathrm{i}}{ }^{\mathrm{CS} 2 \mathrm{j}}\right)$. Thus,

$$
\begin{aligned}
& \alpha^{\mathrm{CS} 2 \_\mathrm{i} \_n}=\left\{\begin{array}{c}
1 \leftrightarrow \sum_{\mathrm{j}} \Delta \mathrm{kpi}_{\mathrm{i}}^{\mathrm{CS} 2 \_j \_n \_\mathrm{SAM}{ }^{\mathrm{CS} 2} \_\mathrm{j}} \geq \Delta^{\mathrm{min}} \mathrm{kpi}_{\mathrm{i}}{ }^{\mathrm{CS} 2 \_\mathrm{j}} \\
0
\end{array}\right. \\
& \alpha^{\mathrm{CS} 2 \_j \_n}=\left\{\begin{array}{c}
1 \leftrightarrow \sum_{\mathrm{j}} \Delta \mathrm{kpi}_{\mathrm{i}}^{\mathrm{CS} 2 \_j \_n \_S A M}{ }^{\mathrm{CS} 2 \_\mathrm{j}} \geq \Delta^{\mathrm{min}} \mathrm{kpi}_{\mathrm{i}} \mathrm{CS}^{\mathrm{CS} \_\mathrm{j}} \\
0
\end{array}\right.
\end{aligned}
$$

CC2. Performance indicator value of enterprise $\mathrm{i}, \mathrm{kpi}_{\mathrm{i}}{ }_{\mathrm{CS} 2 \_\mathrm{i} \_\mathrm{n}}$ obtained when $\mathrm{SAM}^{\mathrm{CS} 2} \mathrm{i}^{\mathrm{i}}$ is computed, considering the alternative $n$, has to be higher than the performance indicator value of enterprise $i$, $\mathrm{kpi}_{i}{ }_{\mathrm{CS}}^{\mathrm{CS}} \mathrm{j} \mathrm{n}$ obtained by enterprise $\mathrm{j}$, corresponding to the alternative $\mathrm{n}$. Therefore,

$$
\alpha^{\mathrm{CS} 2 \_j \_n}=\left\{\begin{array}{c}
1 \leftrightarrow \mathrm{kpi}_{\mathrm{i}}^{\mathrm{CS} 2 \_\mathrm{i} \_\mathrm{n}} \geq \mathrm{kpi}_{\mathrm{i}}^{\mathrm{CS} 2{ }_{-} \_\mathrm{n}} \\
0
\end{array}\right.
$$


CC3. Performance indicator value at network level, calculated for the alternative $\mathrm{n}$ of enterprise $\mathrm{i}$ alternative $n$, has to be higher than the performance indicator value at network level, calculated for the alternative $n$ of enterprise $\mathrm{j}$.

$$
\alpha^{\mathrm{CS} 2 \_j \_n}=\left\{\begin{array}{c}
1 \leftrightarrow \mathrm{kpi}_{\text {net }}^{\mathrm{CS} 2 \_\mathrm{i} \_\mathrm{n}} \geq \mathrm{kpi}_{\text {net }}^{\mathrm{CS} 2 \text { j_n }} \\
0
\end{array}\right.
$$

Hereafter, an example of the CCx defined and selected by enterprises I and $\mathrm{j}$ is illustrated. The fulfilment of the $C \mathrm{Cx}^{\mathrm{i}}, \alpha=\{0,1\}$, is computed according to the following illustrative example (Table 4).

- $\quad$ Enterprise i:

$C C 1^{\mathrm{i}} \cdot \Delta^{\min } \mathrm{kpi}_{\mathrm{i}}^{\mathrm{CS} 2 \mathrm{j}}=1.6$; thus,

- $\quad \alpha^{\mathrm{CS}_{2} \mathrm{in}_{\mathrm{n}}}=1$, given that $\Delta \mathrm{kpi}_{\mathrm{i}}^{\mathrm{CS} 2 \_\mathrm{j} \_\mathrm{n}_{-} \mathrm{SAM}^{\mathrm{CS} 2 \_\mathrm{i}}}=2$ Enterprise $\mathrm{i}$ will select an alternative that achieves the minimum increase defined for the performance indicator. Accordingly, enterprises have to center on $\alpha^{\mathrm{CS} 2} \mathrm{j}_{\mathrm{n}}$

- $\quad \alpha^{\mathrm{CS} 2 \_j \_n}=0$, given that $\Delta \mathrm{kpi}_{\mathrm{i}}{ }_{\mathrm{CS} 2 \_j \_n \_S A M}{ }^{\mathrm{CS} 2 \_\mathrm{j}}=-1$

$\bigcirc \quad \mathrm{CC} 2{ }^{\mathrm{i}} \cdot \mathrm{kpi}_{\mathrm{i}}^{\mathrm{CS} 2 \_\mathrm{i} \_\mathrm{n}}=6$; therefore, $\alpha^{\mathrm{CS} 2 \_j \_n}=0$, given that $\mathrm{kpi}_{{ }_{\mathrm{i}}}^{\mathrm{CS} 2 \_\mathrm{j} \_\mathrm{n}}=4$

$\bigcirc \quad \mathrm{CC}^{\mathrm{i}} . \mathrm{kpi}_{\text {net }}^{\mathrm{CS} 2 \_\mathrm{i} \_\mathrm{n}}=19.5$; therefore $\alpha^{\mathrm{CS} 2 \_ \text {j_n }}=1$, given that $\mathrm{kpi}_{\text {net }}^{\mathrm{CS} 2 \mathrm{j}_{-} \mathrm{n}}=19$

- $\quad$ Enterprise j:

$\mathrm{CC} 1^{\mathrm{j}} \cdot \Delta^{\mathrm{min}} \mathrm{kpi}_{\mathrm{j}}^{\mathrm{CS} 2 \mathrm{i}}=1.5$; thus,

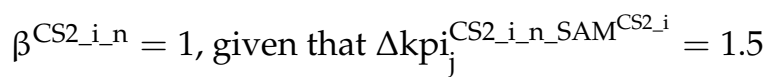

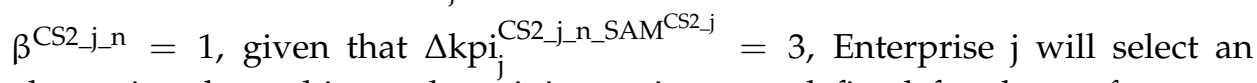
alternative that achieves the minimum increase defined for the performance indicator. Accordingly, enterprises have to center on $\beta^{\mathrm{CS} 2} \mathrm{i} \_\mathrm{n}$

$\bigcirc \quad \mathrm{CC} 2{ }^{\mathrm{j}} . \mathrm{kpi}_{\mathrm{j}}^{\mathrm{CS} 2 \_\mathrm{j} \_\mathrm{n}}=15$; therefore $\beta^{\mathrm{CS} 2 \_\mathrm{i} \_\mathrm{n}}=0$, given that $\mathrm{kpi}_{\mathrm{j}}^{\mathrm{CS} 2 \_\mathrm{i} \_\mathrm{n}}=13.5$

$\bigcirc \quad \mathrm{CC} 3^{\mathrm{j}} \cdot \mathrm{kpi}_{\text {net }}^{\mathrm{CS} 2_{\mathrm{j}_{\mathrm{n}}}}=19$; therefore $\beta^{\mathrm{CS} 2_{\mathrm{in}_{\mathrm{n}}}}=0$, given that $\mathrm{kpi}_{\text {net }}^{\mathrm{CS} 2_{\mathrm{in}_{\mathrm{n}}}}=19.5$

Table 4. CS2: Alternative of solution n.

\begin{tabular}{|c|c|c|c|c|c|c|}
\hline & \multicolumn{3}{|c|}{ Enterprise i } & \multicolumn{3}{|c|}{ Enterprise j } \\
\hline & \multicolumn{2}{|l|}{$\mathbf{k p i}_{\mathbf{i}}$} & \multirow[t]{2}{*}{ str $_{\text {is }}$} & \multicolumn{2}{|l|}{$\mathbf{k p i}_{\mathbf{j}}$} & $\operatorname{str}_{\mathrm{js}}$ \\
\hline $\begin{array}{l}\text { Minimum values } \\
\text { defined for the CC }\end{array}$ & $\Delta^{\min } \mathrm{kpi}_{\mathrm{i}}^{\mathrm{CS} 2 \_j}$ & 1.6 & & $\Delta^{\min } \mathrm{kpi}_{j}{ }_{j}^{\mathrm{CS} 2 \_\mathrm{i}}$ & 1.5 & \\
\hline SAM in NCS & $\mathrm{kpi}_{\mathrm{i}}^{\mathrm{NCS}}$ & 5 & $\begin{array}{l}\text { u_str } \\
\text { is } \\
\text { ti_str } \\
\text { is }\end{array}$ & $\mathrm{kpi}_{\mathrm{j}}^{\mathrm{NCS}}$ & 12 & $\begin{array}{l}\text { u_str }{ }_{j \mathrm{~s}}^{\mathrm{NCS}}{ }^{\mathrm{n}} \mathrm{n} \\
\mathrm{ti} \text { str }{ }_{\mathrm{js}}^{\mathrm{NCS}} \mathrm{n}\end{array}$ \\
\hline \multirow{6}{*}{$\mathrm{SAM}$ in CS2 } & $\Delta \mathrm{kpi}_{\mathrm{i}}{ }_{\mathrm{i}}^{\mathrm{CS} 2}{ }_{-}{ }_{-} \mathrm{n} \_\mathrm{SAM}^{\mathrm{CS} 2 \_\mathrm{i}}$ & 2 & u_str ${ }_{\text {is }}^{\text {CS2_i_n }}$ & 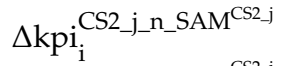 & -1 & u_str ${ }_{\text {is }}^{\text {CS2_j_n }}$ \\
\hline & 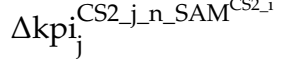 & 1.5 & ti_str & 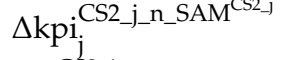 & 3 & 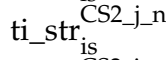 \\
\hline & $\mathrm{kpi}_{\mathrm{i}}^{\mathrm{CS} 2 \_\mathrm{i} \_\mathrm{n}}$ & 6 & u_str ${ }_{j s}^{C S 2}$ i_n & $\mathrm{kpi}_{i}^{\mathrm{CS} 2 \_j \_n}$ & 4 & $\mathrm{u} \_s t r_{j \mathrm{~s}}^{\mathrm{CS} 2}{ }_{\mathrm{j}}^{\mathrm{j}} \mathrm{n}$ \\
\hline & $\mathrm{kpi}_{\mathrm{j}}^{\mathrm{CS} 2 \_\mathrm{i} \_\mathrm{n}}$ & 13.5 & ti_str ${ }_{j S}^{C S 2}$ i_n & $\mathrm{kpi}_{\mathrm{j}}^{\mathrm{CS} 2 \_\mathrm{j} \_\mathrm{n}}$ & 15 & 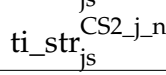 \\
\hline & kpi ${ }_{\text {net }}^{N C S}$ & 17 & & kpi net $_{\text {net }}$ & 17 & \\
\hline & kpi ${ }_{\text {net }}^{\mathrm{CS} 2}$ 2i_n & 19.5 & & $\mathrm{kpi}_{\text {net }}^{\mathrm{CS} 2 \mathrm{j}_{-} \mathrm{n}}$ & 19 & \\
\hline
\end{tabular}


Form the example it can be concluded that although, even in some occasions the CCx is not met $\left(\alpha^{\mathrm{CS} 2 \_j \_n}=0 ; \beta^{\mathrm{CS} 2 \_\mathrm{i} \_\mathrm{n}}=0\right)$, the $\mathrm{kpi}_{\text {net }}^{\mathrm{CS} 1 \_\mathrm{n}}$ is achieved, due to $\mathrm{kpi}_{\text {net }}^{\mathrm{CS} 2 \mathrm{n}} \geq \mathrm{kpi}_{\text {net }}^{\mathrm{NCS}}$.

STEP 7. Definition of the iterative process stopping rule

Stopping rule examples are listed below:

- Maximum amount of iterations agreed by all the CN partners (m_max)

- When kpi ${ }_{\text {net }}^{\mathrm{CS}} \mathrm{n}$ - $\mathrm{kpi}_{\text {net }}^{\mathrm{NCS}}$

- A value of $\mathrm{kpi}_{\text {net }}^{\mathrm{CS} 2 \mathrm{n}}$ is reached

- $\quad \alpha^{\mathrm{CS} 2}{ }_{-} \mathrm{i} n \mathrm{n}=1$ and $\beta^{\mathrm{CS} 2 \_\mathrm{i} \_\mathrm{n}}=1$, so that the alternative selected is the proposed in enterprise $\mathrm{i}$

- $\quad \alpha^{\mathrm{CS} 2 \_ \text {j_n }}=1$ and $\beta^{\mathrm{CS} 2 \_ \text {j_n }}=1$, so that the alternative selected is the proposed in enterprise $\mathrm{j}$

- The difference between values of the two proposed alternatives is minimum

- $\Delta \mathrm{kpi}_{\mathrm{i}}^{\mathrm{CS} 2 \_\mathrm{j} \_n \_S A M^{\mathrm{CS} 2}{ }_{-} \mathrm{i}}$ is within a lower and upper bound established by the CN partners

- A high percentage of $\mathrm{CN}$ enterprises decide that $\alpha^{\mathrm{CS} 2 \_j \_n}=1$ or $\beta^{\mathrm{CS} 2 \_\mathrm{i} \_\mathrm{n}}=1$

STEP 8. Selection of the alternative of solution $n$ from SAM ${ }^{\mathrm{CS} 2{ }_{-} \mathrm{i}}$ and SAM $\mathrm{M}^{\mathrm{CS} 2 \mathrm{j}}$

Considering the solution obtained in the SAM ${ }^{\mathrm{CS} 2}$ :

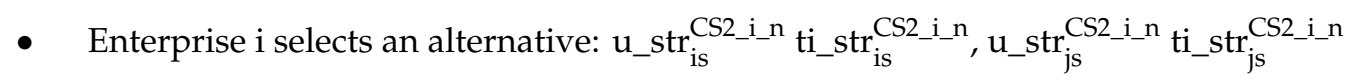

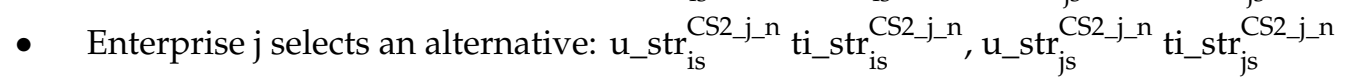

- $\mathrm{n}$ is the value assigned to the alternative chosen, and is consecutively assigned $\mathrm{n}=[1,2, \ldots, \mathrm{n}]$. The first selected alternative would commonly be the one that achieves the optimum value for the enterprise performance indicator, $\max . \mathrm{kpi}_{\mathrm{i}}^{\mathrm{CS} 2 \_\mathrm{n}}$. The selected alternative coincides with the first iteration of the NP_CS2; thus, $\mathrm{n}=\mathrm{m}$

STEP9. Compute the SAM ${ }^{\mathrm{CS} 2}$ considering the results of the selected alternative (n)

Once the solution alternative $\mathrm{n}$ is selected, each $\mathrm{CN}$ enterprise computes the SAM ${ }^{\mathrm{CS} 2}$ :

- Enterprise $\mathrm{i}$ computes the $\mathrm{SAM}^{\mathrm{CS} 2}{ }_{-}^{\mathrm{i}} \mathrm{n}$ considering the solution alternative selected,

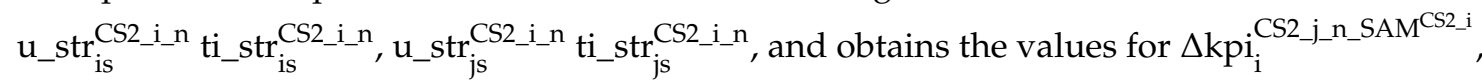

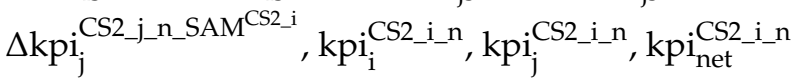

- Enterprise $\mathrm{j}$ computes the $\mathrm{SAM}^{\mathrm{CS} 2} \mathrm{j}_{-} \mathrm{n}$ considering the solution alternative selected,

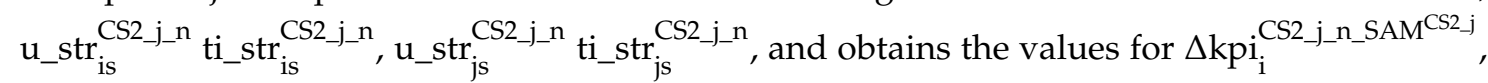
$\Delta \mathrm{kpi}_{\mathrm{j}}^{\mathrm{CS} 2 \_\mathrm{j} \_n \_S A M^{\mathrm{CS} 2}{ }_{\mathrm{j}}}, \mathrm{kpi}_{\mathrm{i}}^{\mathrm{CS} 2 \mathrm{j}_{-} \mathrm{n}}, \mathrm{kpi}_{\mathrm{j}}^{\mathrm{CS} 2 \_\mathrm{j} \_\mathrm{n}}, \mathrm{kpi}_{\text {net }}^{\mathrm{CS} 2 \_\mathrm{j} n}$

STEP 10. Share the decision variables values, given the selected alternatives

- Enterprise $\mathrm{i}$ share with enterprise $\mathrm{j}$ the decision variables values, given the selected alternative n:

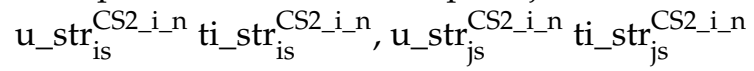

- $\quad$ Enterprise $\mathrm{j}$ share with enterprise $\mathrm{i}$ the decision variables values, given the selected alternative $\mathrm{n}$ :

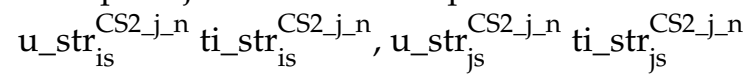

STEP 11. Compute the SAM ${ }^{\mathrm{CS} 2}$, given the decision variables values in other $\mathrm{CN}$ enterprises

The CN enterprises compute the SAM ${ }^{\mathrm{CS} 2}$ using the decision variables values shared in step 10. 
- Enterprise i computes SAM ${ }^{\mathrm{CS} 2}$ using the decision variables values of alternative $\mathrm{n}$ selected by

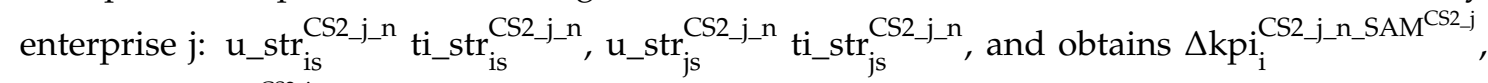

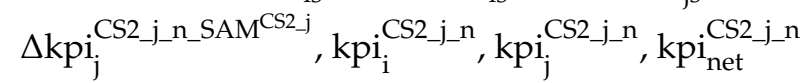

- Enterprise $\mathrm{j}$ computes SAM ${ }^{\mathrm{CS} 2}$ using the decision variables values of alternative $\mathrm{n}$ selected by

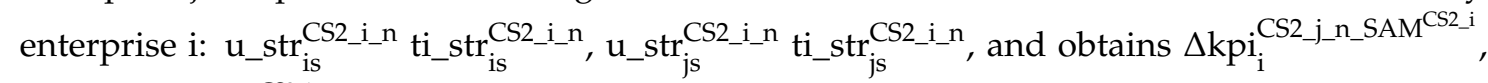

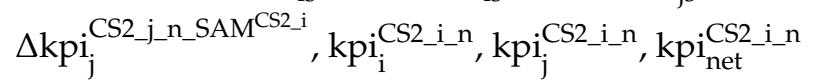

In the solution alternative $\mathrm{n}$ of iteration $\mathrm{m}$, depending on alternative selected by each enterprise, the performance indicators values at the enterprises level $\mathrm{kpi}_{\mathrm{i}}^{\mathrm{CS} 2}, \mathrm{kpi}_{\mathrm{j}}^{\mathrm{CS} 2}$ and network level $\mathrm{kpi}_{\text {net }}^{\mathrm{CS} 2}$ could increase or decrease.

STEP 12. Appraise the solution alternative $n$ selected in enterprise $i$ and $j$

Step 12.1. Appraisal of solution alternative $\mathrm{n}$ provided by enterprise $\mathrm{i}$

If Enterprise i: $\alpha^{\mathrm{CS} 2 \_\mathrm{i} \_n}=1$ and Enterprise $\mathrm{j}: \beta^{\mathrm{CS} 2 \_\mathrm{i} \_\mathrm{n}}=1$ and enterprises are not willing to explore more alternatives, the negotiation is finished and a collaborative negotiated solution is

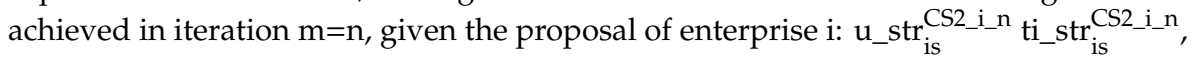
u_str ${ }_{j s}^{C S 2}$ i_n ti_str $_{\text {js }}^{\text {CS2_i_n }}$

Step 12.2. If Enterprise i: $\alpha^{\mathrm{CS} 2 \_\mathrm{i} \_\mathrm{n}}=0$ and Enterprise $\mathrm{j}: \beta^{\mathrm{CS} 2 \_\mathrm{i} \_\mathrm{n}}=0$ or

Enterprise i: $\alpha^{\mathrm{CS} 2 \_\mathrm{i} \_\mathrm{n}}=1$ and Enterprise j: $\beta^{\mathrm{CS} 2 \_\mathrm{i} \_\mathrm{n}}=0$ or

Enterprise i: $\alpha^{\mathrm{CS} 2 \_\mathrm{i} \_n}=0$ and Enterprise j: $\beta^{\mathrm{CS} 2 \_\mathrm{i} \_\mathrm{n}}=1$

Enterprise $i$ and $j$ continue appraising the alternative solution $n$ proposed by enterprise $j$

Step 12.3. Appraisal of alternative solution $n$ provided by enterprise $j$

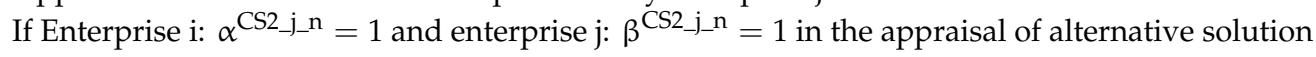
$n$ selected by enterprise $\mathrm{i}$

If Enterprise i: $\alpha^{\mathrm{CS} 2 \_ \text {i_n }}=1$ and Enterprise $\mathrm{j}: \beta^{\mathrm{CS} 2 \_\mathrm{i} \_n}=1$ and identify which alternative, the one proposed by enterprise $\mathrm{i}$ or the one proposed by enterprise $\mathrm{j}$ results on higher performance

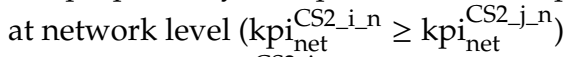

If $\mathrm{kpi}_{\text {net }}^{\mathrm{CS} 2 \_\mathrm{i} \_\mathrm{n}} \geq \mathrm{kpi}_{\text {net }}^{\mathrm{CS}} \mathrm{j}_{-} \mathrm{n}$ a collaborative and negotiated solution is achieved in iteration $\mathrm{m}=\mathrm{n}$,

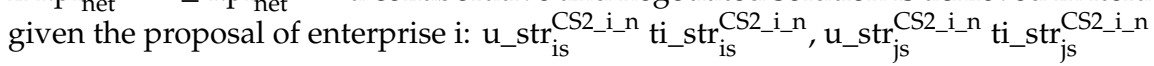

If $\mathrm{kpi}_{\text {net }}^{\mathrm{CS} 2 \mathrm{i} \_\mathrm{n}} \leq \mathrm{kpi}_{\text {net }}^{\mathrm{CS} 2 \mathrm{j} \_\mathrm{n}}$ a collaborative and negotiated solution is achieved in iteration $\mathrm{m}=\mathrm{n}$,

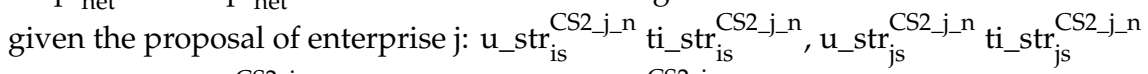

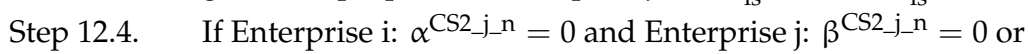

Enterprise i: $\alpha^{\mathrm{CS} 2} \_$j_n $=1$ and Enterprise $\mathrm{j}: \beta^{\mathrm{CS} 2 \_j \_n}=0$ or

Enterprise i: $\alpha^{\mathrm{CS} 2 \_j \_n}=0$ and Enterprise $\mathrm{j}: \beta^{\mathrm{CS} 2 \_j \_n}=1$

The iterative process stopping rule is not met, and steps $8,9,10,11$, and 12 have to be repeated The iterative process stopping rule is met, the negotiation is finished, and a non-collaborative solution is reached

\subsection{Negotiation Process CS3 (NP_CS3)}

The negotiation process described to deal with the CS3 is depicted in Figure 7. NP_CS3 enables $\mathrm{CN}$ partners to jointly estimate influence values thanks to a full sharing of information, which includes the strategies formulated, the performance indicators, and the data related to such strategies and performance indicators. NP_CS3 will enable enterprises to negotiate the values of the decision variables $\mathrm{u}_{\_} \mathrm{str}_{\text {is }}, \mathrm{ti}_{-} \mathrm{str}_{\text {is }}$. Table 5 lists the parameters used in the NP_CS3. The steps to follow in the NP_CS3 are detailed in the following sections. 


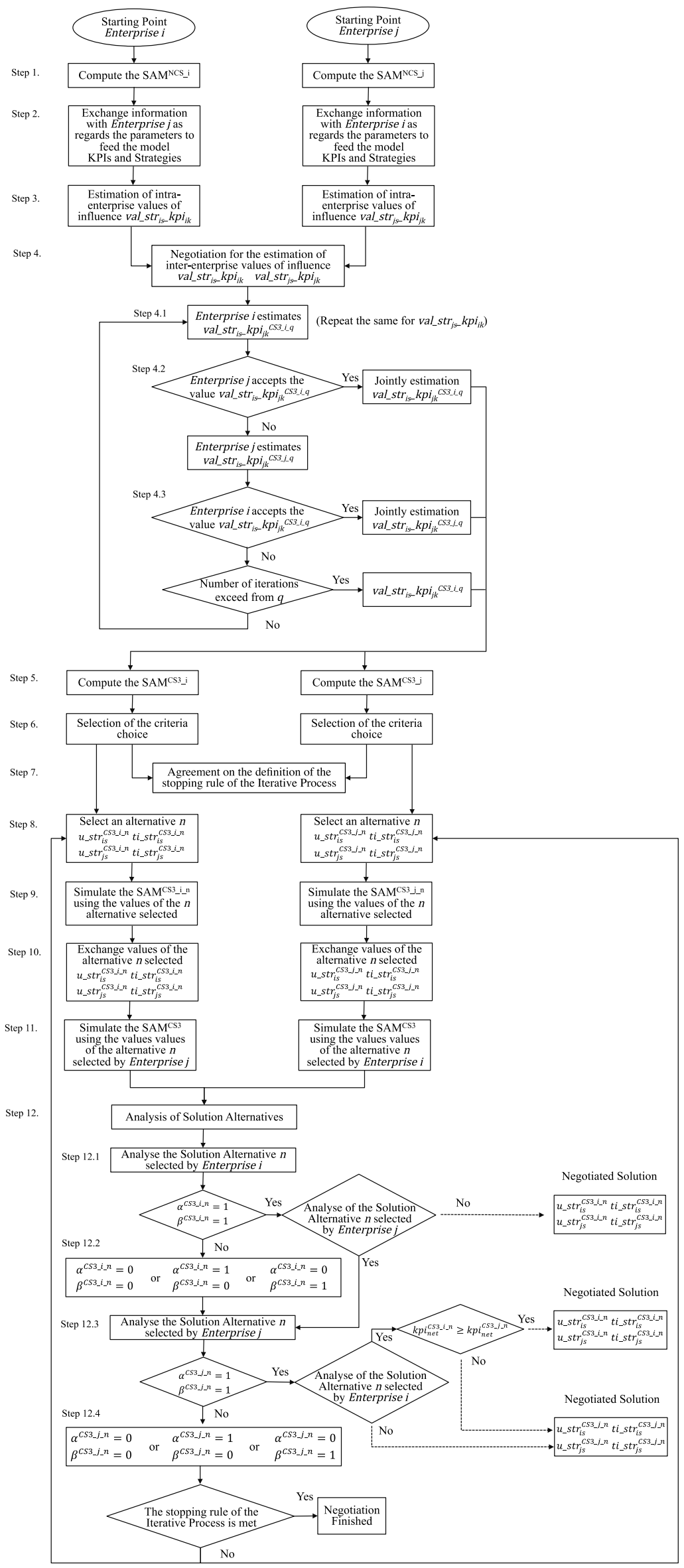

Figure 7. Negotiation Process CS3. 
Table 5. NP_CS3 Parameters.

\begin{tabular}{|c|c|}
\hline Notation & Definition \\
\hline $\mathrm{kpi}_{\mathrm{ik}}$ & Enterprise i performance indicators \\
\hline val_str ${ }_{i s \_} k_{p p i}$ & 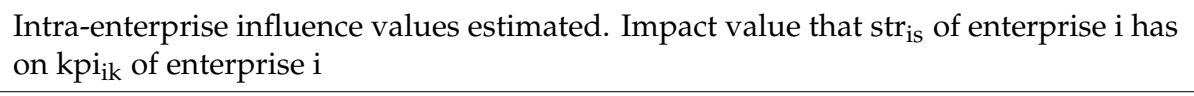 \\
\hline val_str ${ }_{i s \_k p i}{ }_{j k}$ & 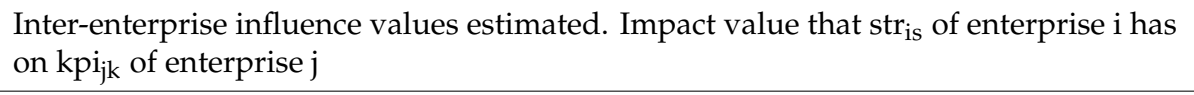 \\
\hline q & $\begin{array}{l}\text { Maximum number of iterations consented by all the } \mathrm{CN} \text { enterprises to negotiate the } \\
\text { estimated influence values (val_stris_kpijk) }\end{array}$ \\
\hline val_str ${ }_{i s \_}$kpi $_{j \mathrm{jk}} \mathrm{CS} 3 \_\mathrm{i} \_\mathrm{q}$ & $\begin{array}{l}\text { Enterprise i estimated influence values, computed considering the impact that a } \operatorname{str}_{\text {is }} \\
\text { has on the } \mathrm{kpi}_{\mathrm{jk}} \text { of enterprise } \mathrm{j} \text {, in the iteration } \mathrm{q} \text {, given the CS3 }\end{array}$ \\
\hline val_str ${ }_{\text {is_- }}$ kpi $_{j \mathrm{jk}}$ CS3_j_q & $\begin{array}{l}\text { Enterprise } \mathrm{j} \text { estimated influence values, computed considering the impact that a } \operatorname{str}_{\mathrm{is}} \\
\text { has on the } \mathrm{kpi}_{\mathrm{jk}} \text { of enterprise } \mathrm{j} \text {, in the iteration } \mathrm{q} \text {, given the CS3 }\end{array}$ \\
\hline $\mathrm{n}$ & $\begin{array}{l}\text { Identifier number for the alternative of solution selected to solve the SAM, using the } \\
\text { output of CS3 }\left(\mathrm{SAM}^{\mathrm{CS} 3}{ }^{\mathrm{i}}\right), \mathrm{n}=[1,2, \ldots, \mathrm{n}]\end{array}$ \\
\hline $\mathrm{m}$ & Identifier number for the iteration, where $\mathrm{m}=\mathrm{n}$ \\
\hline m_max & $\begin{array}{l}\text { Maximum number of iterations consented by all the } \mathrm{CN} \text { enterprises to negotiate the } \\
\text { alternatives generated }\end{array}$ \\
\hline SAM ${ }^{\mathrm{NCS}}{ }_{-} \mathrm{i}$ & SAM calculated in enterprise i given that NCS is applied \\
\hline SAMCS3_i & SAM calculated in enterprise i given that CS3 is applied \\
\hline SAMCS3_i_n & 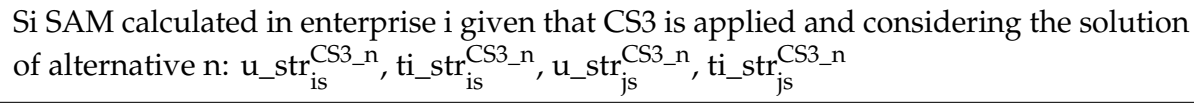 \\
\hline $\mathrm{kpi}_{\text {net }}^{\mathrm{NCS}}$ & Network performance indicator value $\mathrm{kpi}_{\text {net }}$ given the NCS solution \\
\hline $\mathrm{kpi}_{\mathrm{i}}^{\mathrm{NCS}}$ & Enterprise i performance indicator value $\left(\mathrm{kpi}_{\mathrm{i}}\right)$ given the NCS solution \\
\hline u_str ${ }_{\text {is }}^{N C S}$ & Enterprise i units of strategy value $\left(\mathrm{u}_{\text {_str }} \mathrm{is}_{\mathrm{is}}\right)$ given the NCS solution \\
\hline ti_str ${ }_{i s}^{N C S}$ & Enterprise i start time value of $\operatorname{str}_{\text {is }}\left(\mathrm{ti}_{-} \mathrm{str}_{\mathrm{is}}\right)$ given the NCS solution \\
\hline $\mathrm{kpi}_{\mathrm{i}}^{\mathrm{CS} 3 \_\mathrm{i} \_\mathrm{n}}$ & $\begin{array}{l}\text { Enterprise i performance indicator value } \mathrm{kpi}_{\mathrm{i}} \text { considering the influences of all the } \\
\text { strategies activated in each CN enterprise (enterprise } \mathrm{i} \text {; enterprise } \mathrm{j} \text { ), obtained by } \\
\text { enterprise } \mathrm{i} \text { when } \mathrm{SAM} \text { is computed given the CS3 }\left(\mathrm{SAM}^{\mathrm{CS} 3}{ }_{-}^{\mathrm{i}} \text { ) of alternative } \mathrm{n}\right.\end{array}$ \\
\hline $\mathrm{kpi}_{\mathrm{j}}^{\mathrm{CS} 3 \_\mathrm{i} \_\mathrm{n}}$ & $\begin{array}{l}\text { Enterprise } j \text { performance indicator value } \mathrm{kpi}_{\mathrm{j}} \text { considering the influences of all the } \\
\text { strategies activated in each CN enterprise (enterprise } \mathrm{i} \text {; enterprise } \mathrm{j} \text { ), obtained by } \\
\text { enterprise } \mathrm{j} \text { when SAM is computed given the CS3 }\left(\mathrm{SAM}^{\mathrm{CS}}{ }_{-}{ }_{\mathrm{j}} \text { ) of alternative } n\right.\end{array}$ \\
\hline u_str ${ }_{\text {is }}^{\mathrm{CS} 3}$ & $\begin{array}{l}\text { Set of solutions for the value of the units of strategy to be activated }\left(u_{-} \operatorname{str}_{\text {is }}\right) \text { in } \\
\text { enterprise } i \text { when SAM is computed given the CS3 (SAM }{ }^{C S 3} \_ \text {j) }\end{array}$ \\
\hline ti_str ${ }_{\text {is }}^{\mathrm{CS} 3}$ & $\begin{array}{l}\text { Set of solutions for the value of the initial time of activation of the strategy }\left(\operatorname{ti}_{-} \operatorname{str}_{\text {is }}\right) \\
\text { formulated in enterprise } i \text { when when SAM is computed given the CS3 (SAM }{ }^{\text {CS3 } j \text { ) }} \text { ) }\end{array}$ \\
\hline u_str ${ }_{\text {is }}^{C S 3 \_i \_n ~}$ & $\begin{array}{l}\text { Value of the units of strategy } \operatorname{str}_{i s} \text { to be activated }\left(u_{-} s_{1}{ }_{i s}\right) \text { in enterprise } i \text {; obtained by } \\
\text { enterprise } i \text { when SAM is computed given the CS3 }\left(\mathrm{SAM}^{\mathrm{CS} 3} \mathrm{i}\right) \text {, corresponding to the } \\
\text { alternative } \mathrm{n}\end{array}$ \\
\hline ti_str ${ }_{\text {is }}^{\text {CS3_i_n }}$ & $\begin{array}{l}\text { Value of the initial time of activation of } \operatorname{strategy} \operatorname{str}_{\text {is }}\left(\operatorname{ti}_{-} \operatorname{str}_{\text {is }}\right) \text { formulated in enterprise } \mathrm{i} \text {; } \\
\text { and obtained by enterprise } \mathrm{i} \text { when SAM is computed given the CS3 }\left(\mathrm{SAM}^{\mathrm{CS} 3}{ }^{\mathrm{i}}\right) \text {, } \\
\text { corresponding to the alternative } \mathrm{n}\end{array}$ \\
\hline u_str ${ }_{j s}^{C S 3 \_i \_n}$ & 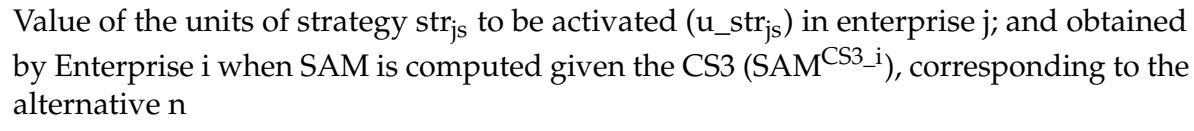 \\
\hline ti_str ${ }_{j s}^{C S 3 \_i \_n ~}$ & $\begin{array}{l}\text { Value of the initial time of activation of } \operatorname{strategy~} \operatorname{str}_{\mathrm{js}}\left(\mathrm{ti}_{-} \mathrm{str}_{\mathrm{js}}\right) \text { formulated in enterprise } \mathrm{i} \text {; } \\
\text { and obtained by enterprise } \mathrm{i} \text { when SAM is computed given the CS3 }\left(\mathrm{SAM}^{\mathrm{CS} 3 \_\mathrm{i}}\right) \text {, } \\
\text { corresponding to the alternative } \mathrm{n}\end{array}$ \\
\hline
\end{tabular}


Table 5. Cont.

\begin{tabular}{|c|c|}
\hline Notation & Definition \\
\hline $\mathrm{kpi}_{\text {net }}^{\mathrm{CS} 3 \text { i_n }}$ & $\begin{array}{l}\text { Value of the kpi }{ }_{\text {net }} \text { obtained by enterprise } \mathrm{i} \text { when SAM is computed given the CS3 } \\
\left(\mathrm{SAM} \mathrm{CS}^{\mathrm{CS}} \mathrm{i}\right) \text {, corresponding to the alternative } \mathrm{n}\end{array}$ \\
\hline$\Delta \mathrm{kpi}_{\mathrm{i}}^{\mathrm{CS} 3 \_\mathrm{j} \_\mathrm{n} \_\mathrm{SAM}}{ }^{\mathrm{CS} 3 \_\mathrm{i}}$ & 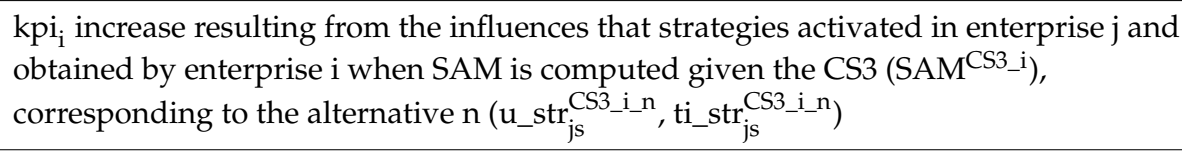 \\
\hline 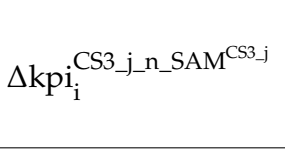 & 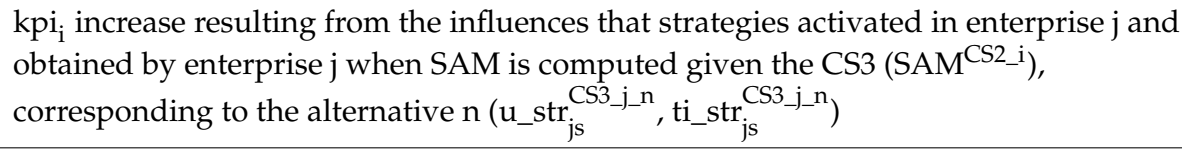 \\
\hline$C C x^{i}$ & Enterprise i criterion choice $x$ \\
\hline$C C x^{j}$ & Enterprise $\mathrm{j}$ criterion choice $\mathrm{x}$ \\
\hline$\Delta^{\min } \mathrm{kpi}_{\mathrm{i}}{ }^{\mathrm{CS} 3}{ }_{-j}$ & $\begin{array}{l}\mathrm{kpi}_{\mathrm{i}} \text { minimum increase reflecting the influences of strategies activated in enterprise } \mathrm{j} \text {, } \\
\text { given the CS3 solution defined by Enterprise i }\end{array}$ \\
\hline$\alpha^{\mathrm{CS} 3 \_\mathrm{i} \_n}$ & $\begin{array}{l}1 \text { if the rule of negotiation established by enterprise } i \text { is accomplished, taking into } \\
\text { account the results of the alternative } n \text { selected by enterprise } i \text {, obtained from the } \\
\text { SAMCS3_i application } \\
0 \text { otherwise }\end{array}$ \\
\hline$\alpha^{\mathrm{CS} 3 \_\mathrm{j} \_n}$ & 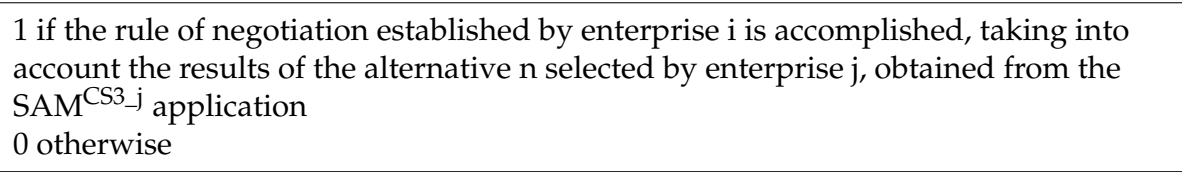 \\
\hline$\beta^{\mathrm{CS} 3 \_\mathrm{i} \_n}$ & $\begin{array}{l}1 \text { if the rule of negotiation established by enterprise } j \text { is accomplished, taking into } \\
\text { account the results of the alternative } n \text { selected by enterprise } i \text {, obtained from the } \\
\text { SAM }{ }^{\text {CS3_i }} \text { application } \\
0 \text { otherwise }\end{array}$ \\
\hline$\beta^{\mathrm{CS} 3 \_\mathrm{j} \_n}$ & 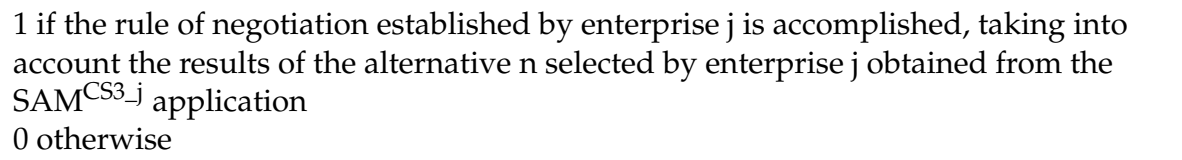 \\
\hline
\end{tabular}

\section{STEP 1. Compute the SAM in the NCS $\left(\mathrm{SAM}^{\mathrm{NCS} \_\mathrm{i}}\right)$}

Each $\mathrm{CN}$ enterprise computes the SAM in by only considering the data of their performance indicators and strategies, calculating the

- Performance indicator value at enterprise level

$$
\begin{array}{ll}
\bigcirc & \text { Enterprise i: } \mathrm{kpi}_{\mathrm{i}}^{\mathrm{NCS}} \\
& \text { Enterprise } \mathrm{j}: \mathrm{kpi}_{\mathrm{j}}{ }^{\mathrm{NCS}}
\end{array}
$$

- Decision variables value

Enterprise i: activated strategy units $\mathrm{u}_{-} \mathrm{str} \mathrm{tis}_{\mathrm{NCS}}$, and activation start time ti_str ${ }_{\text {is }}^{\mathrm{NCS}}$

Enterprise j: $u_{-}$str $_{j \mathrm{~s}}^{\mathrm{NCS}}$, $\mathrm{ti}_{-} \mathrm{str}_{\mathrm{js}}^{\mathrm{NCS}}$

Network performance is computed considering the sum of the performance indicators of each enterprise, $\mathrm{kpi}_{\text {net }}^{\mathrm{NCS}}=\mathrm{kpi}_{\mathrm{i}}^{\mathrm{NCS}}+\mathrm{kpi}_{\mathrm{j}}^{\mathrm{NCS}}$.

STEP 2. Performance indicators parameters and strategies parameters exchanged to feed the SAM ${ }^{C S 3}$

Performance indicators parameters and strategies parameters are exchanged. The definition of the units of strategy $u_{-} \operatorname{str}_{\text {is }}$ is also shared to calculate the SAM ${ }^{\mathrm{CS} 3}$. 
As regards the performance indicators,

- Enterprise $\mathrm{i}$ interchanges data of its performance indicators with enterprise $\mathrm{j}$, this is $\mathrm{kpi}_{\mathrm{ik}}, \mathrm{kpi}_{\mathrm{ik} \_} \mathrm{min}$, Threshold_kpi $i_{i k}$, and $\mathrm{w}_{\mathrm{ik}}$

- Enterprise $\mathrm{j}$ interchanges data of its performance indicators with enterprise $\mathrm{i}$, this is $\mathrm{kpi}_{\mathrm{jk}}, \mathrm{w}_{\mathrm{jk}}$, Threshold_kpi $i_{j k}$, kpi $_{j k} \_$min

As regards the strategies,

- Enterprise $\mathrm{i}$ interchanges with enterprise $\mathrm{j}$ information about the code and definition of the strategies $\left(\mathrm{u} \_s \mathrm{st}_{\mathrm{i} 1}, \mathrm{u} \_\mathrm{str}_{\mathrm{i} 2}, \ldots, \mathrm{u} \_\mathrm{str}_{\mathrm{is}}\right)$ and the parameters associated, d1_str $\mathrm{is}, \mathrm{d} 2 \_s \mathrm{tr}_{\mathrm{is}}, \mathrm{d} 4 \_\mathrm{str}_{\mathrm{is}}$ and c_stris

- Enterprise $\mathrm{j}$ interchanges with enterprise $\mathrm{i}$ information about the code and definition of the

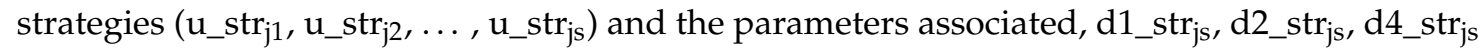
and c_str ${ }_{j s}$ The value for the budget is also shared among the enterprises.

- $\quad$ Enterprise $i$ : shares the budget value $\left(b_{i}\right)$ with enterprise $j$

- $\quad$ Enterprise $\mathrm{j}$ : shares the budget value $\left(b_{\mathrm{j}}\right)$ with enterprise $\mathrm{i}$

In order to maintain confidentially with the shared parameter values, parameters of cost and budget can be pre-processed and assigned values that are proportional to one another. This step needs as many meetings as necessary to exchange the values of the performance indicators and strategies.

STEP 3. Estimate the influence values at the intra-enterprise level (val_str $\left.{ }_{\mathrm{is} \_} \mathrm{kpi}_{\mathrm{ik}}\right)$.

Enterprise $\mathrm{i}$ determines the intra- and inter-enterprise influence values val_str ${ }_{\mathrm{is} \_} \mathrm{kpi}_{\mathrm{ik}}$

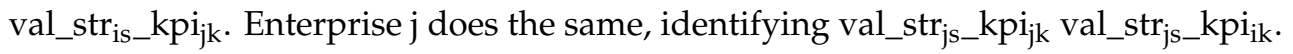

STEP 4. Negotiate the influence values estimated at the inter-enterprise level (val_str ${ }_{\mathrm{is} \_} \mathrm{kpi}_{\mathrm{jk}}$ )

A negotiation process is initialised to agree on the influence values estimated at the inter-enterprise level. First, the number of iterations needed for estimating val_str ${ }_{\mathrm{is} \_} \mathrm{kpi}_{\mathrm{jk}}$ is defined, parameter $\mathrm{q}$. Second, an estimated value for val_str ${ }_{j s \_} k$ i $_{i k}$ is proposed by enterprise $j$, if enterprise i does not agree with such estimation, and viceversa, the negotiation process is started:

Step 4.1 Enterprise i proposes an estimation of val_str ${ }_{i s \_} \mathrm{kpi}_{\mathrm{jk}} \mathrm{CS}_{-} \mathrm{i}_{-} \mathrm{q}$, in the iteration $\mathrm{q}$.

Step 4.2 Enterprise $\mathrm{j}$ appraises the value val_str ${ }_{\mathrm{is} \_} \mathrm{kpi}_{\mathrm{jk}} \mathrm{CS3}_{-} \mathrm{i}_{-} \mathrm{q}$ given by Enterprise $\mathrm{i}$ in iteration $\mathrm{q}$.

If Enterprise $\mathrm{j}$ agrees with the value given to val_str $\mathrm{is}_{-} \mathrm{kpi}_{\mathrm{jk}} \mathrm{CS} 3 \_\mathrm{i} \_\mathrm{q}$ the negotiation finishes, and a

collaborative estimation is achieved for val_str ${ }_{\text {is_- }} \mathrm{kpi}_{\mathrm{jk}} \mathrm{CS} 3 \mathrm{i}_{-} \mathrm{q}$.

If Enterprise j does not agree with the value val_str ${ }_{i s \_} \mathrm{kpi}_{\mathrm{jk}} \mathrm{CS} 3 \_\mathrm{i} \_\mathrm{q}$, Enterprise j estimates a new value for val_str ${ }_{\mathrm{i} \_} \mathrm{kpi}_{\mathrm{jk}} \mathrm{CS3} \_\mathrm{j} \_\mathrm{q}$.

Step 4.3 Enterprise i appraises the value val_str ${ }_{i s \_} \mathrm{kpi}_{\mathrm{jk}} \mathrm{CS}_{-} \mathrm{j}_{-} \mathrm{q}$ given by Enterprise $\mathrm{j}$ in iteration $\mathrm{q}$. If Enterprise i agrees with the value given to val_str ${ }_{i s} \_\mathrm{kpi}_{\mathrm{jk}} \mathrm{CS}_{-} \mathrm{j}_{-} \mathrm{q}$, the negotiation is finished, and a collaborative estimation is achieved for val_str ${ }_{i s \_} \mathrm{kpi}_{\mathrm{jk}} \mathrm{CS3}_{-} \mathrm{j} \_\mathrm{q}$.

If Enterprise i does not agree with the value val_str ${ }_{i s \_} \mathrm{kpi}_{j \mathrm{k}} \mathrm{CS}_{-} \mathrm{j}_{-} \mathrm{q}$ and the maximum number of iterations is not reached (q), step 4.1 is repeated.

If Enterprise i does not agree with the value val_str ${ }_{i s \_} \mathrm{kpi}_{\mathrm{jk}} \mathrm{CS}_{3} \mathrm{j}_{\mathrm{j}} \mathrm{q}$ but $\mathrm{q}$ is reached, the negotiation is finished, and the value for val_str ${ }_{\mathrm{is} \_} \mathrm{kpi}_{\mathrm{jk}} \mathrm{CS} 3 \_\mathrm{i} \_\mathrm{q}$ remains the one proposed by Enterprise $\mathrm{i}$, which defines the strategy $\operatorname{str}_{\text {is }}$.

STEP 5. Compute the SAM given the CS3 (SAM ${ }^{\mathrm{CS} 3}{ }_{-}^{\mathrm{i}}$ )

Each CN partner computes its own model, SAM ${ }^{\mathrm{CS} 3}{ }_{-} \mathrm{i}$ and SAM $\mathrm{SS}_{-}^{\mathrm{C}}$, , using the data exchanged and estimated. All the CN partners have the same input data; therefore, the solution of the SAM ${ }^{\text {CS2_i }}$

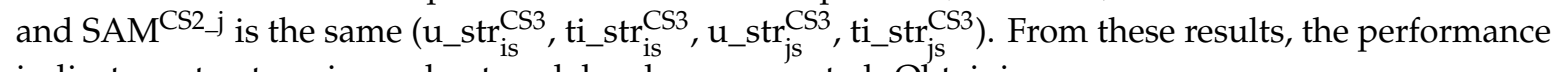
indicators at enterprise and network level are computed. Obtaining 
- Performance indicator value at network level: kpi ${ }_{\text {net }}^{\text {CS3 }}$;

- Performances indicator value at enterprise level: $\mathrm{kpi}_{\mathrm{i}}^{\mathrm{CS} 3}$ and $\mathrm{kpi}_{\mathrm{j}}^{\mathrm{CS} 3}$;

- Decision variables values: $\mathrm{u} \_s \operatorname{st}_{\mathrm{is}}^{\mathrm{CS} 3}, \mathrm{ti} \_s \operatorname{st}_{\mathrm{is}}^{\mathrm{CS} 3}, \mathrm{u}_{-} \mathrm{str}_{\mathrm{j} \mathrm{s}}^{\mathrm{CS} 3}, \mathrm{ti} \_\mathrm{str}_{\mathrm{js}}^{\mathrm{CS} 3}$.

The calculation of SAM ${ }^{\mathrm{CS} 3}$ in each of the $\mathrm{CN}$ enterprises results in a set of solutions, from which one is optimal and rest are considered near optimal. Each solution provided by SAM ${ }^{\mathrm{CS} 3}$ is set as an alternative, being as much alternatives as solutions. $\mathrm{N}$ is the maximum number of solution alternatives. The solution of the SAM ${ }^{\mathrm{CS} 3}$ corresponding to the alternative $\mathrm{n}$ is obtained.

- Performance indicator value at network level:

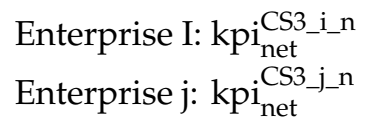

- Performance indicators values at enterprise level

Enterprise i: $\mathrm{kpi}_{\mathrm{i}}^{\mathrm{CS} 3 \_\mathrm{i} \_\mathrm{n}}$ and $\mathrm{kpi}_{\mathrm{j}}^{\mathrm{CS} 3 \_\mathrm{i} \_\mathrm{n}}$

Enterprise $\mathrm{j}: \mathrm{kpi}_{\mathrm{i}}{ }^{\mathrm{CS} 3 \_\mathrm{j} \_\mathrm{n}}$ and $\mathrm{kpi}_{\mathrm{j}}{ }^{\mathrm{CS} 3 \_\mathrm{j} \_\mathrm{n}}$

- Values of the decision variables

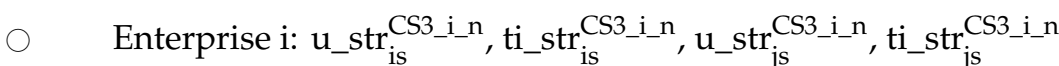

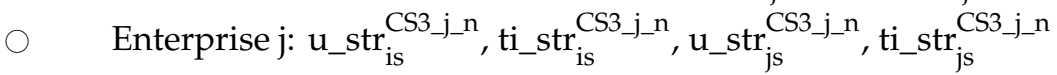

STEP 6. Criteria choice selection $\left(C C x^{\mathrm{i}}\right)$

$C C x^{i}$ enables enterprises to connect the SAM results with their objectives. Three examples of CCx can be seen in step 6 of CS2.

STEP 7. Definition of the iterative process stopping rule

A set of examples to define stopping rules are given in CS1 and CS2.

STEP 8. Selection of the alternative of solution $n$ from SAM ${ }^{\mathrm{CS} 3 \_\mathrm{i}}$ and $\mathrm{SAM}^{\mathrm{CS} 3}{ }_{-}$( (a solution of the $\mathrm{SAM}^{\mathrm{CS} 3 \_\mathrm{i}}$ and $\mathrm{SAM}^{\mathrm{CS} 3}{ }_{-} \mathrm{j}$ )

Considering the solution obtained in the SAM ${ }^{\mathrm{CS} 3}$,

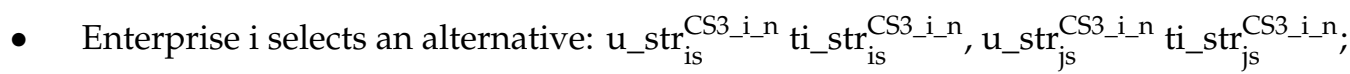

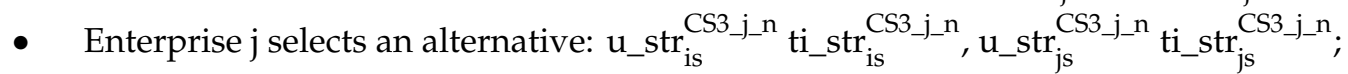

- $\mathrm{n}$ is the value assigned to the alternative chosen, and is consecutively assigned $n=[1,2, \ldots, n]$. The first selected alternative would commonly be the one that achieves the optimum value for the enterprise performance indicator, max. $\mathrm{kpi}_{\mathrm{i}}^{\mathrm{CS} 3 \_\mathrm{n}}$. The selected alternative coincides with the first iteration of the NP_CS3; thus, $\mathrm{n}=\mathrm{m}$.

STEP 9. Compute the SAM ${ }^{\mathrm{CS} 3}$ considering the results of the selected alternative (n)

Once the solution alternative $\mathrm{n}$ is selected, each $\mathrm{CN}$ enterprise computes the $\mathrm{SAM}^{\mathrm{CS} 3}$ :

- Enterprise $\mathrm{i}$ computes the $\mathrm{SAM}^{\mathrm{CS} 3 \_\mathrm{i} n \mathrm{n}}$ considering the solution alternative selected

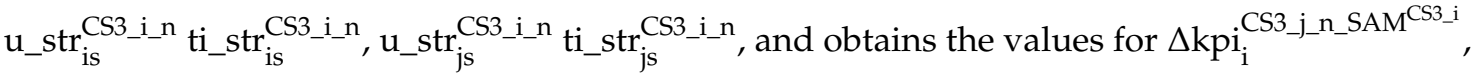

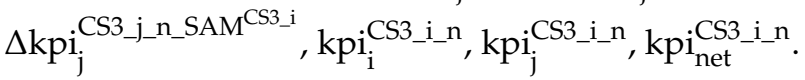


- Enterprise $\mathrm{j}$ computes the $\mathrm{SAM}^{\mathrm{CS} 3}{ }_{-}{ }_{\mathrm{n}} \mathrm{n}$ considering the solution alternative selected:

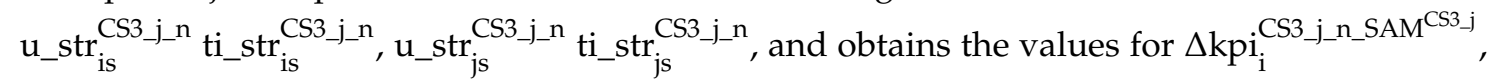

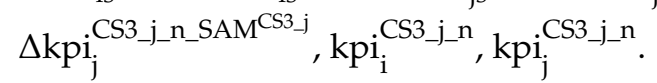

STEP 10. Share the decision variables values, given the selected alternatives

- Enterprise i shares with Enterprise $j$ the decision variables values, given the selected alternative n:

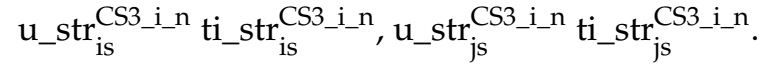

- Enterprise $j$ shares with Enterprise $i$ the decision variables values, given the selected alternative $n$ :

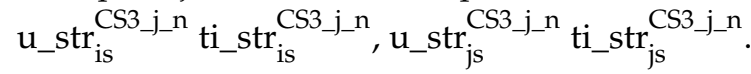

STEP 11. Compute the SAM ${ }^{\mathrm{CS} 3}$, given the decision variables values in other $\mathrm{CN}$ enterprises

Each Enterprise computes the SAM ${ }^{\mathrm{CS} 3}$ considering the values of the decision variables exchanged in STEP 10.

- Enterprise i computes SAM ${ }^{\mathrm{CS} 3}$ using the decision variables values of alternative $\mathrm{n}$ selected by

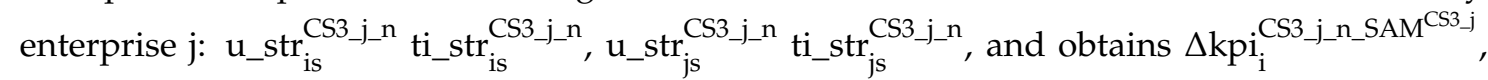

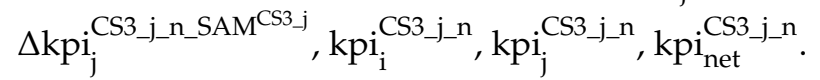

- Enterprise $\mathrm{j}$ computes $\mathrm{SAM}^{\mathrm{CS} 3}$ using the decision variables values of alternative $\mathrm{n}$ selected by

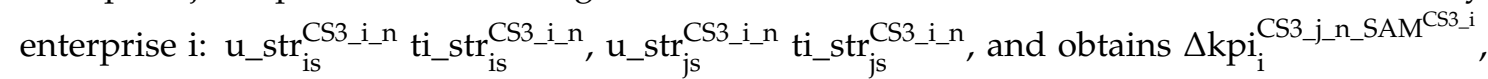

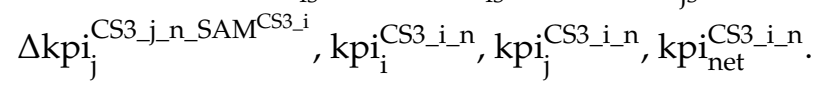

STEP 12. Appraise the solution alternative $n$ selected in enterprise $i$ and $j$

Step 12.1. Appraisal of solution alternative $\mathrm{n}$ provided by enterprise $\mathrm{i}$

If Enterprise i: $\alpha^{\mathrm{CS} 3 \_\mathrm{i} \_\mathrm{n}}=1$, Enterprise j: $\beta^{\mathrm{CS} 3 \_\mathrm{i} \_\mathrm{n}}=1$, and enterprises are not willing to explore more alternatives, the negotiation is finished, and a collaborative negotiated solution is achieved

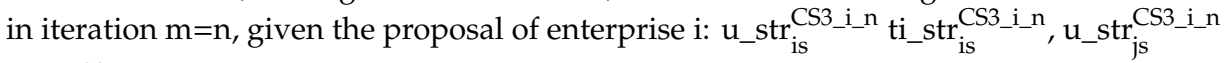
ti_str ${ }_{j \mathrm{js}}^{\mathrm{CS}} \mathrm{i}_{-} \mathrm{n}$.

Step 12.2. If Enterprise i: $\alpha^{\mathrm{CS} 3 \_\mathrm{i} \_\mathrm{n}}=0$ and Enterprise j: $\beta^{\mathrm{CS} 3 \_\mathrm{i} \_\mathrm{n}}=0$ or

Enterprise i: $\alpha^{\mathrm{CS} 3 \_\mathrm{i} \_\mathrm{n}}=1$ and Enterprise j: $\beta^{\mathrm{CS} 3 \_\mathrm{i} \_\mathrm{n}}=0$ or

Enterprise i: $\alpha^{\mathrm{CS} 3 \_\mathrm{i} \_\mathrm{n}}=0$ and Enterprise j: $\beta^{\mathrm{CS} 3 \_\mathrm{i} \_\mathrm{n}}=1$

Enterprise $i$ and $j$ continue appraising the alternative solution $n$ proposed by Enterprise $j$.

Step 12.3. Appraisal of alternative solution $\mathrm{n}$ provided by Enterprise $\mathrm{j}$

If Enterprise i: $\alpha^{\mathrm{CS} 3 \_\mathrm{i} \_\mathrm{n}}=1$ and Enterprise $\mathrm{j}: \beta^{\mathrm{CS} 3 \_\mathrm{i} \_\mathrm{n}}=1$ in the appraisal of alternative solution $\mathrm{n}$ selected by enterprise $\mathrm{i}$

If Enterprise i: $\alpha^{\mathrm{CS} 3 \_\_\_n}=1$ and Enterprise j: $\beta^{\mathrm{CS} 3 \_j \_n}=1$ and identify which alternative, the one proposed by enterprise $i$ or the one proposed by enterprise $j$, results on higher performance at network level ( $\mathrm{kpi}_{\text {net }}^{\mathrm{CS3} i \_n} \geq \mathrm{kpi}_{\text {net }}^{\mathrm{CS}} \_$__n ) If $\mathrm{kpi}_{\text {net }}^{\mathrm{C} \mathrm{CS3}_{-} \mathrm{i} \mathrm{n}} \geq \mathrm{kpi}_{\text {net }}^{\mathrm{CSS} j \_\mathrm{n}}$ a collaborative and negotiated solution is achieved in iteration $\mathrm{m}=\mathrm{n}$,

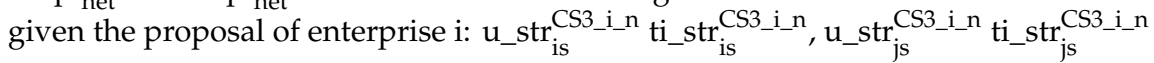
If $\mathrm{kpi}_{\text {net }}^{\mathrm{CS3}}{ }^{\mathrm{C} \mathrm{i} n} \leq \mathrm{kpi}_{\text {net }}^{{ }_{\mathrm{C}} \mathrm{CS} 3 \mathrm{j} \_\mathrm{n}}$ a collaborative and negotiated solution is achieved in iteration $\mathrm{m}=\mathrm{n}$,

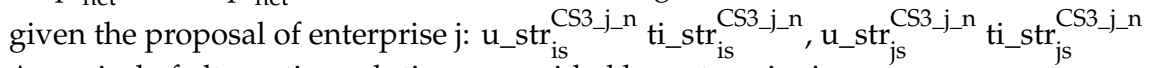
Appraisal of alternative solution $n$ provided by enterprise $j$

If Enterprise i: $\alpha^{\mathrm{CS} 3 \_\_n}=1$ and Enterprise $\mathrm{j}: \beta^{\mathrm{CS} 3 \_j \_n}=1$, the negotiation is finished and a collaborative negotiated solution is achieved in iteration $m=n$, given the proposal of enterprise $j$ :

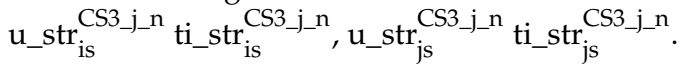


Step 12.4. If Enterprise i: $\alpha^{\mathrm{CS} 3 \_j \_n}=0$ and Enterprise $\mathrm{j}: \beta^{\mathrm{CS} 3 \_j \_n}=0$ or

Enterprise i: $\alpha^{\mathrm{CS} 3 \_j \_n}=1$ and Enterprise $\mathrm{j}: \beta^{\mathrm{CS} 3{ }_{-} \mathrm{j}_{\_} \mathrm{n}}=0$ or

Enterprise i: $\alpha^{\mathrm{CS} 3 \_j \_n}=0$ and Enterprise $\mathrm{j}: \beta^{\mathrm{CS} 3 \_\mathrm{j} \_\mathrm{n}}=1$

The iterative process stopping rule is not met, and steps $8,9,10,11$, and 12 have to be repeated. The iterative process stopping rule is met, the negotiation is finished, and a non-collaborative solution is reached.

\section{Conclusions}

One of the key challenges in supply chain management is the coordination of independent participants in order to achieve the common goal of optimizing market conditions. The strategies alignment model is a rigorous mechanism capable of recognizing the organizational complexity of the $\mathrm{CN}$.

A negotiation approach to support the collaborative process of strategies alignment (SA-NA) is proposed in this paper with the aim of dealing with such operation complexity, in which collaborative partners pursue different goals that are sometimes contradictory. The SA-NA consists of three negotiation processes to assist enterprises in making decisions that align so that the enterprises of the $\mathrm{CN}$ achieve their performance objectives while simultaneously maximising performance at the network level. A detailed description of the three negotiation processes is presented, with the aim of complementing the strategies alignment (SA) [4] approach. The three negotiation processes described correspond to the three collaborative levels identified, which are characterised by the amount of information shared when dealing with the strategies' alignment process from a collaborative perspective. The negotiation process established at the first collaborative scenario (NP_CS1) is characterized by a low exchange of information. In NP_CS2, a medium exchange of information is established, while NP_CS3 is characterized by a full exchange of information and the collaborative estimation of all the

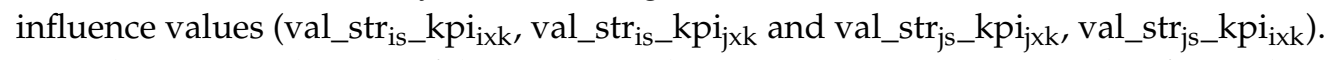

The main application of the strategies alignment negotiation approach is focused on $\mathrm{CN}$ enterprises that are willing to collaborate and align their strategies. In this regard, the $\mathrm{CN}$ should be characterised by a balanced dominance within the CN and an establishing DDM process. The proposed SAM_NP supports $\mathrm{CN}$ enterprises with regard to the strategies to be adopted, so that they are aligned. The three negotiation processes proposed at each collaboration level, including NP_CS1, NP_CS2, and NP_CS3, allow enterprises to reach a solution that benefits all the $\mathrm{CN}$ enterprises, so that the performance indicators at enterprise level are achieved and the performance indicator at the network level is maximised, obtaining the optimal or near optimal values. With the implementation of the strategies' alignment negotiation approach, sustainable and stable $\mathrm{CN}$ relationships are achieved. Moreover, the visibility of the $\mathrm{CN}$ enterprises is also improved due to the partners sharing information about their strategies and performance indicators to a greater or lesser extent.

Enterprises participating in the strategies' alignment process have to know that, within the strategies' alignment collaborative approach the improvement of the performance indicators is not always achieved, due to some partners could gain at the expense of other partners' loses. Nevertheless, the SAM is prepared to achieve the enterprises' minimum performance levels, given the $k p i_{i k}$ min parameter, which refers to the minimum level to be achieved by the performance indicator $k$ defined in enterprise i.

The objective of this paper is achieved because the proposed strategies alignment negotiation approach fulfils the future research lines defined in Andres and Poler [4] - the application of the SAM in a distributed context, in which decentralized decision making is carried out.

The negotiation process in the level 3 of collaboration has been applied in two real cases in the automotive industry and food distribution sector. Future research should apply the strategies alignment negotiation approach in levels 1 and 2 of collaboration. To this extent, each enterprise of the $\mathrm{CN}$ could be represented in a multi-agent system model, each one behaving according to the SAM. Thus, the results obtained in a particular agent could be managed as the inputs of the rest of the 
agents, which represent the individual $\mathrm{CN}$ enterprises. Finally, the SA-NA could be automated by using a decentralised database, collecting in each $\mathrm{CN}$ enterprise the information required to feed the strategies alignment negotiation approach.

Obstacles identified in the negotiation approach refer to the information exchange among the $\mathrm{CN}$ partners. The different levels of collaboration have enabled us to relate the degree of information exchanged with a specific collaboration degree. Nevertheless, academic researchers and industry professionals need to go further in the research of digital transformation as a novel approach to deal with information sharing. In this regards, Industry 4.0 can be considered as a base research to deal with the information exchange challenges. As stated by Park et al. [32], emerging techniques such as artificial intelligence (AI) are to be developed in order to facilitate the information exchange and the process of negotiation, which can be applied to the strategies alignment collaborative process addressed in the current paper.

Author Contributions: This work forms part of the research of B.A., supervised by V.J.B. in the industrial context. The work developed by B.A. and V.J.B. proposes a negotiation approach to deal with the strategies' alignment process in the collaborative context. B.A. modelled the problem and jointly with V.B.J. defined the different levels of collaboration applied in the negotiation approach. Conceptualization, B.A.; methodology, B.A.; validation V.J.B.; formal analysis, B.A.; investigation, B.A.; resources, V.J.B.; data curation, B.A. and V.J.B.; writing-original draft preparation, B.A. and V.J.B.; writing-review and editing, B.A. and V.J.B.; visualization, B.A. and V.J.B.; supervision V.J.B.; project administration, B.A.; funding acquisition, B.A. All authors have read and agreed to the published version of the manuscript.

Funding: This research was funded by Ayuda Vali+D Formacion-Andres Navarro (ACIF/2012/006). (16 April 2012-16 April 2015) GENERALITAT VALENCIANA.

Conflicts of Interest: The authors declare no conflict of interest.

\section{References}

1. Camarinha-Matos, L.M.; Abreu, A. Performance indicators for collaborative networks based on collaboration benefits. Prod. Plan. Control 2007, 18, 592-609. [CrossRef]

2. Matopoulos, A.; Vlachopoulou, M.; Manthou, V.; Manos, B. A conceptual framework for supply chain collaboration: Empirical evidence from the agri-food industry. Supply Chain Manag. Int. J. 2007, 12, 177-186. [CrossRef]

3. Andres, B.; Poler, R. Models, guidelines and tools for the integration of collaborative processes in non-hierarchical manufacturing networks: A review. Int. J. Comput. Integr. Manuf. 2016, 29, 166-201.

4. Andres, B.; Poler, R. A decision support system for the collaborative selection of strategies in enterprise networks. Decis. Support Syst. 2016, 91, 113-123. [CrossRef]

5. Schneeweiss, C. Distributed decision making in supply chain management. Int. J. Prod. Econ. 2003, 84, 71-83. [CrossRef]

6. Li, X.; Wang, Q. Coordination mechanisms of supply chain systems. Eur. J. Oper. Res. 2007, 179, 1-16. [CrossRef]

7. Alemany, M.M.E.; Alarcón, F.; Lario, F.C.; Boj, J.J. An application to support the temporal and spatial distributed decision-making process in supply chain collaborative planning. Comput. Ind. 2011, 62, 519-540. [CrossRef]

8. Jung, H.; Chen, F.; Jeong, B. Decentralized supply chain planning framework for third party logistics partnership. Comput. Ind. Eng. 2008, 55, 348-364. [CrossRef]

9. Camarinha-Matos, L.M. Collaborative Networks in Industry and the role of PRO-VE. Int. J. Prod. Manag. Eng. 2014, 2, 53-57. [CrossRef]

10. Macedo, P.; Camarinha-Matos, L. Value Systems Alignment Analysis in Collaborative Networked Organizations Management. Appl. Sci. 2017, 7, 1231. [CrossRef]

11. Camarinha-Matos, L.M.; Afsarmanesh, H. Collaborative networks: A new scientific discipline. J. Intell. Manuf. 2005, 16, 439-452. [CrossRef]

12. Fonseca, L.M. Strategic drivers for implementing sustainability programs in portuguese organizations-let's listen to aristotle: From triple to quadruple bottom line. Sustain. J. Rec. 2015, 8, 136-142. [CrossRef] 
13. Fonseca, L.M.; Domingues, J.P.; Pereira, M.T.; Martins, F.F.; Zimon, D. Assessment of circular economy within Portuguese organizations. Sustainability 2018, 10, 2521. [CrossRef]

14. Shafiei, F.; Sundaram, D.; Piramuthu, S. Multi-enterprise collaborative decision support system. Expert Syst. Appl. 2012, 39, 7637-7651. [CrossRef]

15. Kebriaei, H.; Majd, V.J. A simultaneous multi-attribute soft-bargaining design for bilateral contracts. Expert Syst. Appl. 2009, 36, 4417-4422. [CrossRef]

16. Gupta, A.; Maranas, C.D. Managing demand uncertainty in supply chain planning. Comput. Chem. Eng. 2003, 27, 1219-1227. [CrossRef]

17. Dudek, G.; Stadtler, H. Negotiation-based collaborative planning between supply chains partners. Eur. J. Oper. Res. 2005, 163, 668-687. [CrossRef]

18. Wang, K.J.; Chen, M.J. Cooperative capacity planning and resource allocation by mutual outsourcing using ant algorithm in a decentralized supply chain. Expert Syst. Appl. 2009, 36, 2831-2842. [CrossRef]

19. Goetschalckx, M.; Fleischmann, B. Strategic network planning. In Supply Chain Management and Advanced Planning, 3rd ed.; Concepts, Models Software and Case Studies; Springer: Berlin/Heidelberg, Germany, 2005; pp. 117-137.

20. Pibernik, R.; Sucky, E. An approach to inter-domain master planning in supply chains. Int. J. Prod. Econ. 2007, 108, 200-212. [CrossRef]

21. Chen, C.L.; Wang, B.W.; Lee, W.C. Multiobjective optimization for a multienterprise supply chain network. Ind. Eng. Chem. Res. 2003, 42, 1879-1889. [CrossRef]

22. Andres, B.; Poler, R. A Methodology to Share Profits and Costs in Non-Hierarchical Networks. In Annals of Industrial Engineering 2012: Industrial Engineering Overcoming the Crisis; Prado-Prado, J.C., Arca, J.G., Eds.; Springer: Berlin/Heidelberg, Germany, 2014; pp. 341-349.

23. Ertogral, K.; Wu, S.D. A Bargaining Game for Supply Chain Contracting; Work Paper; Department of Industrial and Systems Engineering, Lehigh University: Bethlehem, PA, USA, 2001; pp. 1-26.

24. Kirche, E.T.; Kadipasaoglu, S.N.; Khumawala, B.M. Maximizing supply chain profits with effective order management: Integration of Activity-Based Costing and Theory of Constraints with mixed-integer modelling. Int. J. Prod. Res. 2005, 43, 1297-1311. [CrossRef]

25. Hall, N.G.; Potts, C.N. Supply chain scheduling: Batching and delivery. Oper. Res. 2003, 51, 566-584. [CrossRef]

26. Rahmawati, Y.; Utomo, C.; Zawawi, N.A.W.A. BIM and e-negotiation practices in AEC consulting businesses. Sustainability 2019, 11, 1911. [CrossRef]

27. Clipa, A.M.; Clipa, C.I.; Danilet, M.; Andrei, A.G. Enhancing sustainable employment relationships: An empirical investigation of the influence of trust in employer and subjective value in employment contract negotiations. Sustainability 2019, 11, 4995. [CrossRef]

28. Liu, X.; Ma, Z.; Liang, D. Personality effects on the endorsement of ethically questionable negotiation strategies: Business ethics in Canada and China. Sustainability 2019, 11, 3097. [CrossRef]

29. Ferrada, F.; Camarinha-Matos, L.M. Simulation model to estimate emotions in collaborative networks. Appl. Sci. 2019, 9, 5202. [CrossRef]

30. Andres, B. An Approach to Support the Strategies Alignment Process in Collaborative Networks. Ph.D. Thesis, Universitat Politècnica de València, Valencia, Spain, 2016.

31. Piedade, F.R.; Azevedo, A.; Bastos, J. Managing Performance to Align the Participants of Collaborative Networks: Case Studies Results. In Collaborative Networks for Sustainable World; Camarinha-Matos, L.M., Boucher, X., Afsarmanesh, H., Eds.; Springer: Berlin/Heidelberg, Germany, 2010; pp. 545-552.

32. Park, J.; Rahman, H.A.; Suh, J.; Hussin, H. A study of integrative bargaining model with argumentation-based negotiation. Sustainability 2019, 11, 6832. [CrossRef]

(C) 2020 by the authors. Licensee MDPI, Basel, Switzerland. This article is an open access article distributed under the terms and conditions of the Creative Commons Attribution (CC BY) license (http://creativecommons.org/licenses/by/4.0/). 